Article

\title{
Transparent Glass-Ceramics Produced by Sol-Gel: A Suitable Alternative for Photonic Materials
}

\author{
Giulio Gorni ${ }^{1}$, Jose J. Velázquez ${ }^{1}{ }^{10}$, Jadra Mosa ${ }^{1}$, Rolindes Balda ${ }^{2,3}$, Joaquin Fernández ${ }^{2,3}$, \\ Alicia Durán ${ }^{1, *}$ and Yolanda Castro ${ }^{1, *}$ \\ 1 Instituto de Cerámica y Vidrio (CSIC), 28049 Madrid, Spain; ggorni@icv.csic.es (G.G.); \\ josvel@icv.csic.es (J.J.V.); jmosa@icv.csic.es (J.M.) \\ 2 Departamento de Física Aplicada I, Escuela Superior de Ingeniería, Universidad del País Vasco UPV/EHU, \\ 48940 Bilbao, Spain; rolindes.balda@ehu.eus (R.B.); joaquin.fernandez@ehu.es (J.F.) \\ 3 Centro de Física de Materiales UPV/EHU-CSIC, 20018 San Sebastian, Spain \\ * Correspondence: aduran@icv.csic.es (A.D.); castro@icv.csic.es (Y.C.)
}

Received: 11 January 2018; Accepted: 27 January 2018; Published: 30 January 2018

\begin{abstract}
Transparent glass-ceramics have shown interesting optical properties for several photonic applications. In particular, compositions based on oxide glass matrices with fluoride crystals embedded inside, known as oxyfluoride glass-ceramics, have gained increasing interest in the last few decades. Melt-quenching is still the most used method to prepare these materials but sol-gel has been indicated as a suitable alternative. Many papers have been published since the end of the 1990s, when these materials were prepared by sol-gel for the first time, thus a review of the achievements obtained so far is necessary. In the first part of this paper, a review of transparent sol-gel glass-ceramics is made focusing mainly on oxyfluoride compositions. Many interesting optical results have been obtained but very little innovation of synthesis and processing is found with respect to pioneering papers published 20 years ago. In the second part we describe the improvements in synthesis and processing obtained by the authors during the last five years. The main achievements are the preparation of oxyfluoride glass-ceramics with a much higher fluoride crystal fraction, at least double that reported up to now, and the first synthesis of $\mathrm{NaGdF}_{4}$ glass-ceramics. Moreover, a new $\mathrm{SiO}_{2}$ precursor was introduced in the synthesis, allowing for a reduction in the treatment temperature and favoring hydroxyl group removal. Interesting optical properties demonstrated the incorporation of dopant ions in the fluoride crystals, thus obtaining crystal-like spectra along with higher efficiencies with respect to xerogels, and hence demonstrating that these materials are a suitable alternative for photonic applications.
\end{abstract}

Keywords: sol-gel; oxyfluoride glass-ceramics; nanocrystal; optical properties

\section{Introduction}

Phosphor materials emit light under exposure to external stimulation, such as an electron beam, light at different wavelengths, voltage or electric field, etc. These materials are widely applied in light-emitting diodes, solar cells, sensing, catalysis, integration in photovoltaic devices, and more recently in biosensing, bioimaging, or medical diagnosis [1-6].

The optical properties of these materials can change drastically depending on the processing parameters. Thus, in the past two decades, interest in studying the synthesis and processing of nanophosphors to develop luminescent materials with high efficiency has increased. The properties of existing devices can be improved by including luminescent phosphors and/or nanocrystalline oxyfluorides doped with lanthanide ions $\left(\mathrm{Ln}^{3+}\right) . \mathrm{Ln}^{3+}$ ions are commonly used as active ions because they show emissions in a wide spectral range, from UV to NIR, and their use in telecom, lasers, lightening, etc. makes them indispensable nowadays. Moreover, their most stable oxidation state is 
$3+$, consisting of partially filled inner $4 \mathrm{f}$ levels screened by outer $5 \mathrm{~s}$ and $5 \mathrm{p}$ orbitals. This allows for maintaining emission energies centered near the same values even in different hosts, making them suitable for applications where certain wavelengths are required. Several studies and applications deal with nanoparticles doped with $\mathrm{Ln}^{3+}$ ions suspended in liquid phase or with phosphor powders. However, for many applications as laser materials, waveguides and optical fibers, lightening devices, etc., solid and easy-to-handle samples are required.

In particular, oxyfluoride nano-glass-ceramics (OxGCs) are attractive materials for photonic applications, because they combine the very low phonon energy of fluoride nanocrystals (NCs) (300-450 $\mathrm{cm}^{-1}$ ) with the high chemical and mechanical stability of oxide glass matrices, especially alumino-silicate ones [7-9]. Moreover, such materials can be cast in several forms to obtain the desired device. However, to maintain the transparency and avoid Rayleigh scattering produced by the quite big difference of refractive index between the oxide glass matrix and fluoride crystals, precise control of the crystal size is mandatory. Hence, to obtain materials with high transparency in the UV-Vis range, NCs with a size lower than $40-50 \mathrm{~nm}$ are required.

The pioneering work about OxGCs, published in 1993 by Wang and Ohwaki [10], in which $\mathrm{Pb}_{x} \mathrm{Cd}_{1-x} \mathrm{~F}_{2}$ fluoride NCs doped with $\mathrm{Er}^{3+}$ and $\mathrm{Yb}^{3+}$ ions were precipitated in a silica-aluminate glass matrix after a proper heat treatment, showed an increase in the Up-Conversion (UC) emission of GCs with respect to precursor glass. Since that paper, the number of publications about transparent GCs has grown exponentially. In the last few decades, many compositions have been studied with the aim of obtaining different crystal phases and using different $\mathrm{Ln}^{3+}$ ions as dopants to obtain enhanced linear and nonlinear optical processes.

The usual method to prepare OxGCs is traditional glass melt-quenching (MQ). This method allows for obtaining several compositions; however, the most studied ones are those based on alumino-silicate matrices, even though there are also some studies of phosphate and fluoride GCs [11,12]. According to the definition of GCs [13], "Glass-ceramics are ceramic materials formed through the controlled nucleation and crystallization of glass". In general, for MQ materials, the crystallization process is performed at temperatures slightly higher than $\mathrm{T}_{\mathrm{g}}\left(\mathrm{T}_{\mathrm{g}}+20-100^{\circ} \mathrm{C}\right)$ to ensure the growth of crystals with a nanometric size that permits maintaining transparency. Moreover, phase separation commonly acts as a precursor for crystallization and the typical crystallization mechanism is a diffusion-controlled process.

The MQ method presents some drawbacks, most of them related to the high temperatures involved during the glass melting. In fact, high melting temperatures $\left(1400-1700^{\circ} \mathrm{C}\right)$ cause relevant fluorine loss, up to $30-40 \%$, thus limiting the final content of crystal phase that can be obtained and resulting in uncontrollable compositions with respect to fluorine and $\mathrm{Ln}^{3+}$ ions. In addition, due to quite common phase separation of the precursor glass due to fluorine immiscibility in oxide glass matrices, it is a challenge to prepare high-quality samples for applications as laser devices or any other that requires high optical quality. Furthermore, heat treatments, in general, are quite long (from $3 \mathrm{~h}$ up to $120 \mathrm{~h}$ ) and thin films cannot be directly obtained, thus limiting the possibility of application as integrated devices. Despite these disadvantages, the MQ method demonstrated the possibility of obtaining OxGCs as bulk materials with enhanced optical properties with respect to precursor glass, and in recent years, the preparation of novel OxGC optical fibers has also been achieved [14-17]. Therefore, MQ is still the most used processing method to obtain OxGCs and is also scalable to an industrial level. Indeed, transparent GC containing up to $75 \%$ of crystal fraction, with a crystal size below $40 \mathrm{~nm}$, are extensively used in telescope mirrors [18].

To overcome previous limitations without giving up the field of OxGCs, many researchers tried different processing methods. In particular, the Sol-Gel (SG) route has been recognized and indicated as a promising alternative process to obtain transparent OxGCs. In fact, SG is a handy, flexible, and quite cheap method to fabricate novel and innovative materials at temperatures much lower than those used for MQ materials. Such low temperatures allow for introducing a higher amount of fluoride NCs with much better dispersion than in MQ compositions. Moreover, because SG is a chemical process using 
a bottom-up approach, high homogeneity can be obtained with no phase separation detected in SG glasses or GCs.

Another important feature of SG is the versatility of the processing method that permits obtaining thin films, powders, and bulk materials. However, many fewer papers about SG OxGCs are reported in the literature compared to those describing materials prepared by MQ [8]. This is mostly associated with the requirement of the optimization of the synthesis method, and in many cases the starting precursor can also affect the final crystal phase. Most of the materials studied have a simple composition that can be easily summarized with the formula:

$$
(100-x) \mathrm{SiO}_{2}-\mathrm{x} \mathrm{M}_{1} \mathrm{~F}_{2} / \mathrm{M}_{1} \mathrm{~F}_{3} / \mathrm{M}_{1} \mathrm{M}_{2} \mathrm{~F}_{4} / \mathrm{M}_{1} \mathrm{M}_{2} \mathrm{~F}_{5},
$$

where $\mathrm{M}_{1}$ and $\mathrm{M}_{2}$ are alkaline, alkaline-earth metals, or lanthanide elements, respectively. More complex glass matrices, where $\mathrm{SiO}_{2}$ is partly substituted with $\mathrm{Al}_{2} \mathrm{O}_{3}$, are also reported in the literature but are quite rare, and even more complex structures have also been prepared but for different applications as biomaterials [19].

SG synthesis typically involves the hydrolysis and polycondensation of metal salts or metal-organic precursors, such as tetraethyl orthosilicate (TEOS), in an alcoholic medium. The active phase and $\mathrm{Ln}^{3+}$ ions are prepared separately using acetates, nitrates, or chlorates as precursors and dissolved using a fluorine acid. The mixing of both solutions, followed by a controlled crystallization, allows for obtaining transparent OxGCs.

Even though the SG method offers potential advantages, they have not been fully exploited, and all the papers published to date describe the preparation of similar compositions containing nominal small crystal fractions (5-10 mol \%), with the real crystal content not being estimated. Furthermore, in many cases only slight changes are added to the already published compositions, the main modifications consisting of changing the dopants and/or their concentration.

In the following sections the most relevant results for several $\mathrm{Ln}^{3+}$ doped OxGCs for optical applications studied to date and prepared by SG are summarized. The results are separated into two sections depending on the crystal phase. A third section regarding oxides and oxychlorides GCs has also been added, while in the last sections we will present the results and improvements introduced by our group in the last five years.

\subsection{Alkaline-Earth Oxyfluoride Glass-Ceramics, $M_{1} F_{2}\left(M_{1}=M g, P b, S r, C a, B a\right), M_{1} M_{2} F_{4}\left(B a M g F_{4}\right)$}

Alkaline-earth fluoride GCs, with the formula $\mathrm{M}_{1} \mathrm{~F}_{2}(\mathrm{M}=\mathrm{Mg}, \mathrm{Pb}, \mathrm{Sr}, \mathrm{Ca}, \mathrm{Ba})$, are useful for photonic applications due to their high optical transparency in a wide spectral range, from (UV) ultraviolet to infrared (IR). $\mathrm{MgF}_{2}$-based materials have been extensively studied for different applications, for example as protective coatings on glass optics due to their low chemical reactivity, low refractive index (1.38), and scratch- and weather-resistance. Even though this review is centered on materials with luminescence properties, $\mathrm{MgF}_{2}$ materials deserve special attention because they have been among the first fluorides produced by SG. Even more interesting is that the synthesis of $\mathrm{MgF}_{2}$ introduced important novelties in the synthesis of OxGCs.

One of the first works reported about $\mathrm{MgF}_{2} \mathrm{NCs}$ and $\mathrm{SiO}_{2}-\mathrm{MgF}_{2}$ materials prepared by SG as bulk and thin films dates back to 1996 [20]. $\mathrm{Mg}\left(\mathrm{OCH}_{3}\right)_{2}$ and $\mathrm{HF}$ were used as $\mathrm{Mg}$ and F sources, respectively, to obtain $\mathrm{MgF}_{2}$ sol. $\mathrm{SiO}_{2}-\mathrm{MgF}_{2}$ sols were also prepared with ratios of (mol \%) 20:80 and 40:60, using tetramethyl orthosilicate (TMOS) as the $\mathrm{SiO}_{2}$ precursor. X-ray diffraction (XRD) showed that $\mathrm{MgF}_{2}$ crystals precipitated in both sol and glass samples, but the crystal growth in $\mathrm{SiO}_{2}-\mathrm{MgF}_{2}$ samples was dramatically slowed $(\sim 15 \mathrm{~nm})$ in comparison with that of pure $\mathrm{MgF}_{2}$ samples $(\sim 115 \mathrm{~nm})$. For $20 \mathrm{SiO}_{2}: 80 \mathrm{MgF}_{2}$ samples, the crystal size maintained the same value. $\mathrm{MgF}_{2} \mathrm{NC}_{\text {s }}$ have been obtained after treatment at different temperatures following the procedure described in [21]. In 1997 Fujihara et al. [22] reported on $\mathrm{MgF}_{2}$ thin films using trifluoracetic acid (TFA) and $\mathrm{Mg}\left(\mathrm{OC}_{2} \mathrm{H}_{5}\right)_{2}$ as a fluorine or magnesium precursor, respectively, with a molar ratio 1:2.6. The most important 
innovation is the use of TFA as a fluorine precursor, together with an explanation of the fluoride NCs' formation. It was assumed that $\mathrm{Mg}\left(\mathrm{OC}_{2} \mathrm{H}_{5}\right)_{2}$ complexes were formed in the xerogel and upon heat treatment, $\mathrm{Mg}^{2+}$ ions react with thermally activated fluorine in $\mathrm{CF}_{3} \mathrm{COO}^{-}$ions to form $\mathrm{MgF}_{2}$ crystals. This decomposition reaction was accompanied by a huge weight loss, around 75\%, as confirmed by Differential Thermal Analysis (DTA) (Figure 1). Some years later it was demonstrated that, thanks to the screening effect of $\mathrm{CF}_{3} \mathrm{COO}$ ions of TFA, metal cations with oxidation state $2+$ or $3+$ are prevented from being incorporated in the $\mathrm{SiO}_{2}$ matrix, making possible subsequent fluoride $\mathrm{NCs}^{\prime}$ precipitation upon heat treatment. Therefore, this work can be considered pioneering and a boost towards the preparation of OxGCs by SG.

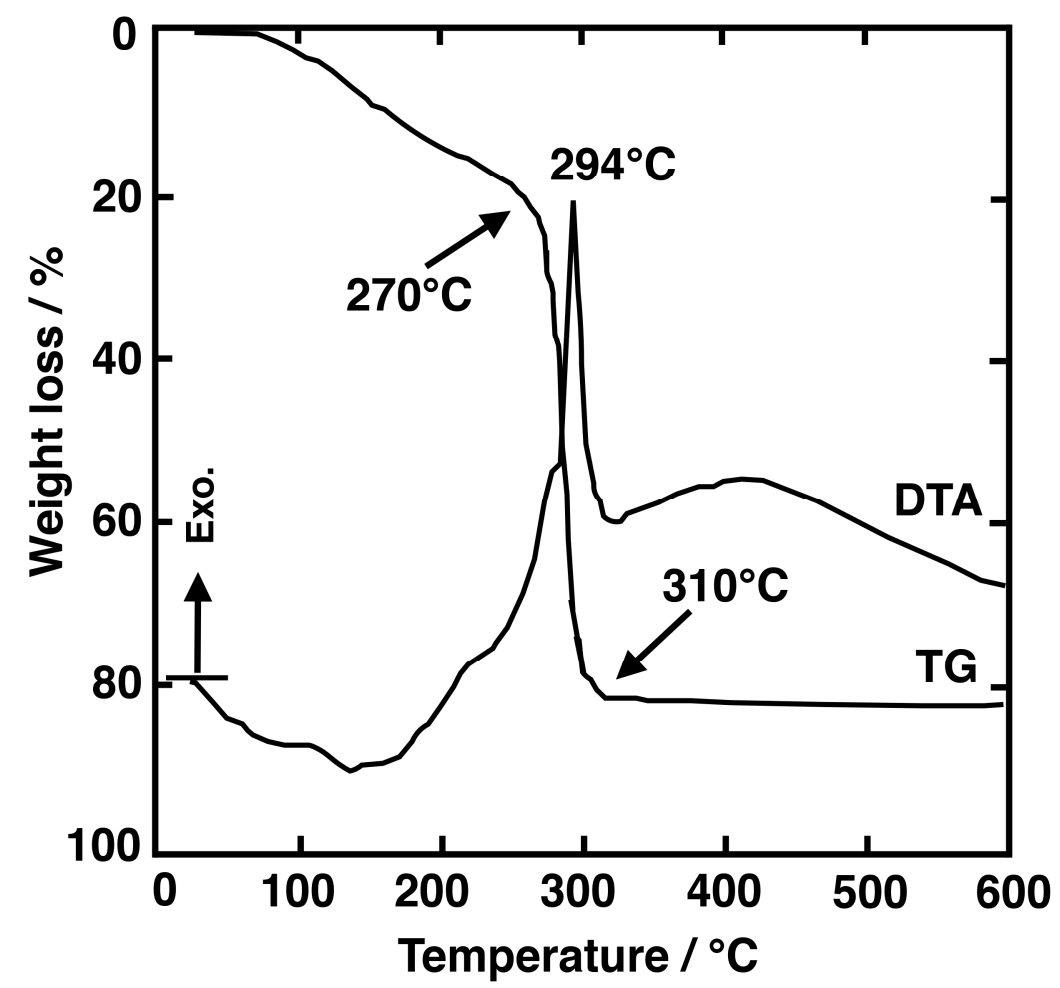

Figure 1. TGA/DTA curve of the $\mathrm{MgF}_{2}$ gel obtained by drying the sol at $80{ }^{\circ} \mathrm{C}$. Figure modified from Figure 4 of [22].

Another phase extensively studied is $\mathrm{PbF}_{2}$. One of the first works associated with $\mathrm{SiO}_{2}-\mathrm{PbF}_{2}$ samples was reported in 2004 by Luo et al. [23]. Bulk materials of composition $90 \mathrm{SiO}_{2}-10 \mathrm{PbF}_{2}$ doped with $\mathrm{Er}^{3+}$ were prepared using TEOS and TFA as the $\mathrm{SiO}_{2}$ or fluorine precursor, respectively. The molar ratio of precursors TEOS: $\mathrm{CH}_{3} \mathrm{CH}_{2} \mathrm{OH}: \mathrm{DMF}: \mathrm{Pb}\left(\mathrm{CH}_{3} \mathrm{COO}\right)_{2}$ :TFA: $\mathrm{H}_{2} \mathrm{O}: \mathrm{HNO}_{3}$ was 1:2:2:0.1:0.6:4:0.4. Upon heat treatment at $300{ }^{\circ} \mathrm{C}$ and $480{ }^{\circ} \mathrm{C} \beta-\mathrm{PbF}_{2} \mathrm{NCs}$ precipitated in the glass matrix. $\mathrm{Er}^{3+}$ ions seemed to be segregated at the surface of the crystallites and hindered the growth of $\mathrm{PbF}_{2} \mathrm{NCs}_{\text {, }}$ thus delaying crystallization and reducing the crystal size from 20 to $9 \mathrm{~nm}$. Other authors reported on UC measurements in bulk materials of the same composition doped with $0.1 \mathrm{Er}^{3+}-0.3 \mathrm{Yb}^{3+}$ [24]. A TEOS:EtOH: $\mathrm{H}_{2} \mathrm{O}: \mathrm{CH}_{3} \mathrm{COOH}$ ratio of 1:4:10:0.5 was used for the $\mathrm{SiO}_{2}$ sol, while the ratio $\mathrm{Ln}\left(\mathrm{CH}_{3} \mathrm{COO}\right)_{3}$ :TFA was 1:4. UC bands showed well-resolved Stark components indicating the incorporation of $\mathrm{Ln}^{3+}$ ions into $\mathrm{PbF}_{2}$ crystals. Results for the same composition doped with $\mathrm{Tm}^{3+}-\mathrm{Yb}^{3+}-\mathrm{Er}^{3+}$ and $\mathrm{Tm}^{3+}-\mathrm{Yb}^{3+}-\mathrm{Ho}^{3+}$ were also reported [25]. In both cases, the color tunability of UC luminescence was obtained, allowing white UC generation. Following the same synthesis and composition of Luo et al. described before, Szpikowska-Sroka et al. published some papers about OxGCs with different dopants [26-28]. After heat treatment, $\mathrm{Eu}^{3+}$ and $\mathrm{Tb}^{3+}$ ions showed an increase in the emission spectra in GC samples with respect to the xerogels due to the incorporation of these ions 
into the NCs. In fact, the asymmetry ratio, $R$, described as the ratio between the two visible emissions $\mathrm{I}\left({ }^{5} \mathrm{D}_{0}-{ }^{7} \mathrm{~F}_{2}\right) / \mathrm{I}\left({ }^{5} \mathrm{D}_{0}-{ }^{7} \mathrm{~F}_{1}\right)$ of $\mathrm{Eu}^{3+}$, gives information about the nature of the environment surrounding the ion. Moreover, the effect of the TFA on the optical properties was also analyzed, showing the best result for a $\mathrm{Pb} / \mathrm{TFA}$ ratio of 5 and corresponding to a crystal fraction of $3 \mathrm{wt} \%$.

$90 \mathrm{SiO}_{2}-10 \mathrm{SrF}_{2}$ transparent GCs doped with $\mathrm{ErF}_{3}(1 \mathrm{~mol} \%)$ were prepared by Yu et al. in 2006 [29]. Samples treated at $300{ }^{\circ} \mathrm{C}$ already showed the precipitation of $\mathrm{SrF}_{2}$ crystals with a size of $10 \mathrm{~nm}$. The same crystal size is maintained for heat treatment up to $800{ }^{\circ} \mathrm{C}$. However, upon excitation at $378 \mathrm{~nm}$ no $\mathrm{Er}^{3+}$ emission was detected unless for samples treated at $800^{\circ} \mathrm{C}$. The authors attributed this phenomenon to the presence of $-\mathrm{OH}$ groups that quench the luminescence. Two years later, the same authors prepared transparent bulk samples of composition $90 \mathrm{SiO}_{2}-10 \mathrm{SrF}_{2}-0.5 \mathrm{ErF}_{3}$ and 97.5 $\left(90 \mathrm{SiO}_{2}-10 \mathrm{SrF}_{2}\right)-2.5 \mathrm{Al}_{2} \mathrm{O}_{3}-0.5 \mathrm{ErF}_{3}(\mathrm{~mol} \%)$ [30]. $\mathrm{Al}_{2} \mathrm{O}_{3}$ was added as the nitrate, with $\mathrm{Al}^{3+}$ acting as a glass network former, replacing $\mathrm{Si}^{4+}$. The introduction of $\mathrm{Al}^{3+}$ to the $\mathrm{SiO}_{2}$ network causes a decrease in non-bridging oxygens, hindering the crystallization of fluoride $\mathrm{NCs}$. The $\mathrm{SiO}_{2}-\mathrm{Al}_{2} \mathrm{O}_{3}$ glass matrix showed higher transparency in the UV region due to lower pore content and the final optical properties were better for this composition treated at $1000{ }^{\circ} \mathrm{C}$. Very intense and visible UC luminescence was observed for GC based on $\mathrm{SiO}_{2}-\mathrm{Al}_{2} \mathrm{O}_{3}$ matrix, as compared to the one with only $\mathrm{SiO}_{2}$.

The first $\mathrm{SiO}_{2}-\mathrm{CaF}_{2}$ transparent GC prepared by SG was reported in 2007 by Zhou et al. [31]. $95 \mathrm{SiO}_{2}-5 \mathrm{CaF}_{2}$ bulk samples doped with $1 \mathrm{~mol} \% \mathrm{ErF}_{3}$ were treated at $900{ }^{\circ} \mathrm{C}$, allowing the precipitation of $\mathrm{CaF}_{2}$ crystals of $20 \mathrm{~nm}$ in size, homogeneously distributed in the amorphous $\mathrm{SiO}_{2}$ matrix. $\mathrm{Er}^{3+}$ incorporation in the crystal phase was tested by Energy-Dispersive X-ray Spectroscopy (EDXS). Only Red UC emission was detected upon $980 \mathrm{~nm}$ excitation. Georgescu et al. prepared $89 \mathrm{SiO}_{2}-5 \mathrm{CaF}_{2}-5 \mathrm{YbF}_{3}-1 \mathrm{ErF}_{3}(\mathrm{~mol} \%) \mathrm{GCs}$ upon heat treatment at $800{ }^{\circ} \mathrm{C}$ [32]. A solid solution of $\left(\mathrm{Ca}_{1-\mathrm{x}} \mathrm{Ln}_{\mathrm{x}}\right) \mathrm{F}_{2+\mathrm{x}}$ crystals was observed by XRD, and both red-green and Violet-UV UC were observed when exciting the samples at $973 \mathrm{~nm}$. The process was described as a two-photon and three-photon absorption process for visible and UV emissions, respectively, upon IR excitation. On the other hand, a different approach was used to prepare $95 \mathrm{SiO}_{2}-5 \mathrm{CaF}_{2} \mathrm{GCs}$ [33]. $\mathrm{Er}^{3+}$-doped $\mathrm{CaF}_{2}$ crystals were previously synthesized by co-precipitation using $\mathrm{Er}\left(\mathrm{NO}_{3}\right)_{3}, \mathrm{Ca}\left(\mathrm{NO}_{3}\right)_{2}$, and ammonium bi-fluoride $\mathrm{NH}_{4} \mathrm{HF}_{2}$ as precursors. Then, $\mathrm{NCs}$ were mixed to $\mathrm{SiO}_{2}$ sol, dried at $50{ }^{\circ} \mathrm{C}$ during one month and heat-treated to obtain bulk materials. The authors considered that conventional SG route does not allow control of the size and quantity of crystals as well as the $\mathrm{Ln}^{3+}$ concentration into the NCs. The optical results showed that the UC emissions increased when passing from xerogels to GCs, the corresponding lifetimes of the ${ }^{4} \mathrm{~F}_{9 / 2}-{ }^{4} \mathrm{I}_{15 / 2}$ emission being $1.3 \mu \mathrm{s}$ and $1.7 \mathrm{~ms}$, respectively. This effect was ascribed to the incorporation of $\mathrm{Er}^{3+}$ into $\mathrm{CaF}_{2} \mathrm{NCs}$ with phonon energy around $460 \mathrm{~cm}^{-1}$.

Another interesting host for $\mathrm{Ln}^{3+}$ ions is $\mathrm{BaF}_{2}$ due to its very low phonon energy, around $320 \mathrm{~cm}^{-1}$. The first $\mathrm{SiO}_{2}-\mathrm{BaF}_{2} \mathrm{SG}$ material was reported in 2006 by Chen et al. [34]. $95 \mathrm{SiO}_{2}-5 \mathrm{BaF}_{2}$ bulk materials were prepared and doped with 0.5 and $1 \mathrm{Er}^{3+}(\mathrm{mol} \%) . \mathrm{BaF}_{2}$ crystals, $2-4 \mathrm{~nm}$ in size, precipitated in the glass matrix after heat treatment at $300{ }^{\circ} \mathrm{C}$. Up to $700{ }^{\circ} \mathrm{C}$, no relevant effects in the crystallization were observed. Over this temperature, the crystal grew up to $10 \mathrm{~nm}$. However, treatment at higher temperature also caused the crystallization of the glass matrix in the form of cristobalite. The incorporation of $\mathrm{Er}^{3+}$ ions into the NCs was revealed due to the shift of the XRD peaks toward higher angles in $\mathrm{Er}^{3+}$-doped samples and by EDXS and Judd-Ofelt calculations. Photoluminescence (PL) emission was detected only for samples treated at $800^{\circ} \mathrm{C}$ and green and red UC emissions were observed upon $980 \mathrm{~nm}$ excitation. The same composition and synthesis were used by Secu et al. when doping materials with $\mathrm{Pr}^{3+}, \mathrm{Sm}^{3+}, \mathrm{Eu}^{3+}, \mathrm{Dy}^{3+}$, and $\mathrm{Ho}^{3+}[35,36]$. Small $\mathrm{BaF}_{2}$ crystals $(\sim 7 \mathrm{~nm})$ were precipitated upon heat treatment at $800^{\circ} \mathrm{C}$ for $1 \mathrm{~h}$. No $\mathrm{Ln}^{3+}$ emission was observed for xerogels except for $\mathrm{Eu}^{3+}$, while for all the GCs typical $4 \mathrm{f}-4 \mathrm{f}$ transitions were observed showing the Stark splitting of the bands (Figure 2). Moreover, the typical $\mathrm{Eu}^{3+}$ emissions in GCs indicated that these ions are effectively incorporated into NCs. The $\mathrm{Eu}^{3+}$ lifetime, measured at $620 \mathrm{~nm}$, increased from 0.3 to $4.7 \mathrm{~ms}$ passing from xerogel to GC. 


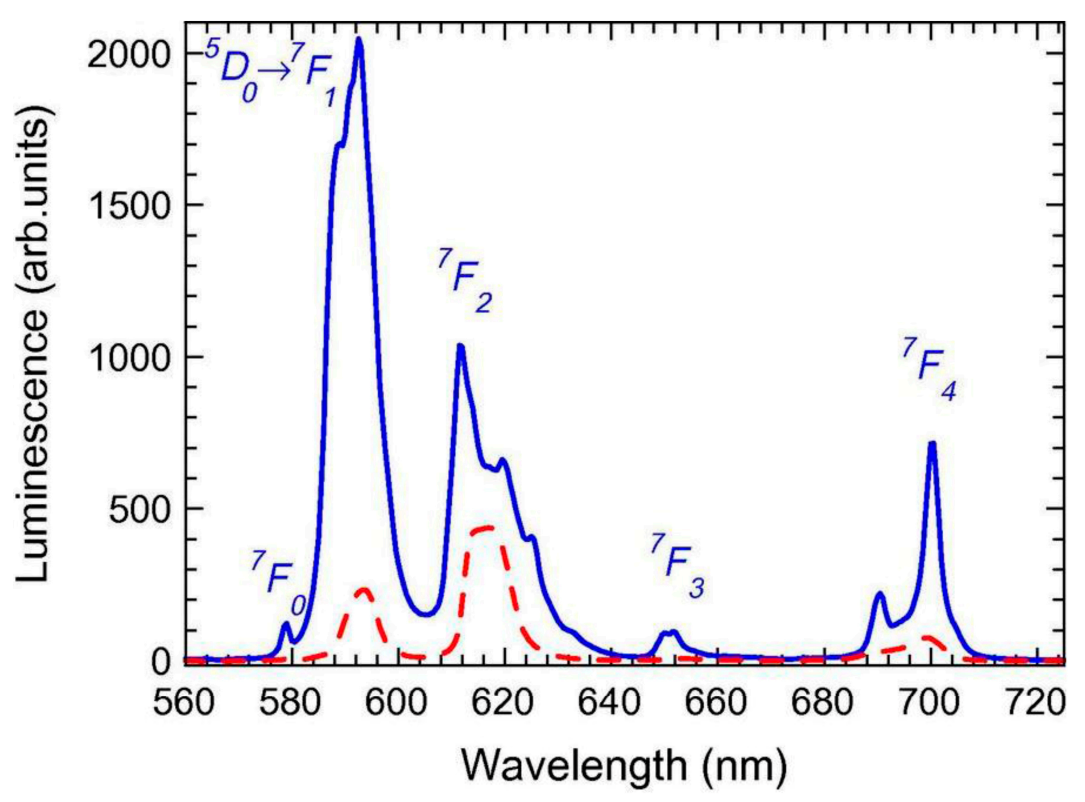

Figure 2. PL spectra recorded on $\mathrm{Eu}^{3+}$-doped xerogel (dotted curve) and GC (solid curve) using $\lambda$ ex. $=394 \mathrm{~nm}[35]$.

To conclude this first section, we mention the preparation of $90 \mathrm{SiO}_{2}-10 \mathrm{BaMgF}_{4}$ films doped with $\mathrm{Eu}^{3+}$ prepared by Fujihara et al. [37]. Upon heat treatment at $750{ }^{\circ} \mathrm{C}$ for $10 \mathrm{~min}$ small $\mathrm{BaMgF}_{4}$ NCs $3 \mathrm{~nm}$ in size, were observed by High-Resolution Transmission Electron Microscopy (HRTEM). By N,N-dimethylformamide (DMF) addition a porous film was obtained, while, without DMF the film was dense. DMF addition also favors crystallization, reducing stresses in films [38]. The corresponding PL measurements only showed $\mathrm{Eu}^{2+}$ emission, meaning that $\mathrm{Eu}^{2+}$ ions are effectively incorporated in the crystal phase, substituting $\mathrm{Ba}^{2+}$ ions. Furthermore, $\mathrm{Eu}^{2+}$ emission was much stronger for porous films due to higher photon confinement, producing an increase in the absorption process.

1.2. Lanthanides Oxyfluoride Glass-Ceramics, $M_{1} F_{3}\left(M_{1}=L a, Y, G d\right)$ and $M_{1} M_{2} F_{4}, M_{1} M_{2} F_{5}\left(M_{1}=N a, K\right.$, $\left.L i ; M_{2}=G d, Y\right)$

\subsection{1. $\mathrm{M}_{1} \mathrm{~F}_{3}$}

Oxyfluoride GCs in which one element of the NCs former is a $\mathrm{Ln}^{3+}$ ion are the most studied compositions. In fact, $\mathrm{Ln}^{3+}$ ions are easily replaced by other ions used as dopants, due to their similar ionic radius and equal charge. Moreover, some ions as $\mathrm{Gd}^{3+}$ are known to act as sensitizers for other ions as $\mathrm{Eu}^{3+}, \mathrm{Tb}^{3+}$, and $\mathrm{Dy}^{3+}$ [39-41], making possible energy transfer (ET) processes and thus making this NC phase attractive for several photonic applications.

Among all the lanthanide crystals, $\mathrm{LaF}_{3}$ is the most studied. Several papers about $\mathrm{LaF}_{3}$ OxGCs have been published since 1998, when Fuhijara et al. described the preparation of $\mathrm{LaF}_{3}$ thin films on silica substrates [42]. In that work, the authors explained the importance of controlling the synthesis and heat treatment process to obtain high-purity $\mathrm{LaF}_{3} \mathrm{NCs}$, avoiding the precipitation of other phases as $\mathrm{LaOF}$. In the following years, the same authors worked extensively in the preparation of $\mathrm{SiO}_{2}-\mathrm{LaF}_{3}$ bulk samples, observing the crystallization of $\mathrm{LaF}_{3} \mathrm{NCs}$ with a size ranging from 10 to $30 \mathrm{~nm}$ [43]. They also studied the influence of TFA on the $\mathrm{LaF}_{3} \mathrm{NCs}^{\prime}$ crystallization, proposing that such formation occurs by the following chemical reaction [44-46]:

$$
\mathrm{La}\left(\mathrm{CF}_{3} \mathrm{COO}\right)_{3} \rightarrow \mathrm{LaF}_{3}+\left(\mathrm{CF}_{3} \mathrm{CO}\right)_{2} \mathrm{O}+\mathrm{CO}+\mathrm{CO}_{2}
$$

However, the authors stated that it is not possible to raise the $\mathrm{LaF}_{3}$ content beyond $10 \mathrm{~mol} \%$ without losing transparency. Therefore, all the papers published after this work concentrated on 
Fujihara's synthesis and composition, just changing the active phase. TMOS was partially or totally replaced by TEOS but the same stoichiometric ratios of $\mathrm{H}_{2} \mathrm{O}$ and TFA were used, bringing little innovation to the synthesis and processing of OxGC materials.

The preparation of transparent $\mathrm{Eu}^{3+}$ doped $\mathrm{SiO}_{2}-\mathrm{LaF}_{3}$ and $\mathrm{SiO}_{2}-\mathrm{LaOF}$ OxGC films, in which $\mathrm{Eu}^{3+}$ ions were incorporated into the $\mathrm{LaF}_{3}$ crystals, resulted in interesting PL emissions [47]. Results showed important differences depending on the sintering temperature and, therefore, on the crystals phase. On the other hand, Ribeiro et al. [48] prepared films with the same composition, finding that for heat treatment between 600 and $900{ }^{\circ} \mathrm{C}$ both $\mathrm{LaF}_{3}$ and $\mathrm{LaOF}$ phases appeared. $\mathrm{Eu}^{3+}$ ions emissions mainly from the ${ }^{5} \mathrm{D}_{0}$ excited state reflected the change in the environment of these ions. They used thin films as planar waveguides at Vis and IR wavelengths, reported losses $\sim 1.8 \mathrm{~dB} / \mathrm{cm}$ at $632.8 \mathrm{~nm}$. However, the authors considered that the intensity of PL measurements depends on the nature of the crystal phase and the presence of $-\mathrm{OH}$ groups that are responsible for PL quenching. At such a high sintering temperature, $-\mathrm{OH}$ groups could be eliminated, but fluorine can be lost, producing a silica matrix rich of lanthanide ions and changing the emission spectra.

$\mathrm{LaF}_{3} \mathrm{OxGC}$ bulk materials were also prepared by other authors. Biswas et al. [49] described the preparation of transparent $95 \mathrm{SiO}_{2}-5 \mathrm{LaF}_{3} \mathrm{GC}$, after densification at $1000{ }^{\circ} \mathrm{C}$, using TEOS instead of TMOS as the $\mathrm{SiO}_{2}$ precursor and a TEOS: $\mathrm{H}_{2} \mathrm{O}: \mathrm{CH}_{3} \mathrm{COOH}$ molar ratio of 1:10:0.5. Optical results showed very good UC efficiency from the IR-to-UV region due to the $\mathrm{Yb}^{3+}-\mathrm{Er}^{3+} \mathrm{ET}$ process, which is enhanced in GCs, suggesting the incorporation of $\mathrm{Er}^{3+}$ ions in the low-phonon environment of $\mathrm{LaF}_{3} \mathrm{NCs}$.

In order to optimize the optical properties, other authors have described the preparation of bulk GC materials with molar ratios $(100-x) \mathrm{SiO}_{2}-\mathrm{xLaF}_{3}(\mathrm{x}=5$ and $10 \mathrm{~mol} \%)$, doped with (0.1-0.5) mol $\%$ of $\mathrm{Ln}^{3+}$ ions and heat treated at temperature up to $1000{ }^{\circ} \mathrm{C}$ [50-55] following a similar synthesis to Biswas et al. Optical results showed that $\mathrm{Eu}^{3+}$ ions could be selectively excited and, even more interesting, opened the way for the estimation of the percentage of ions that are incorporated in the NCs, concluding that at least $50 \%$ are effectively incorporated in $\mathrm{LaF}_{3}$. Another paper [53] described the preparation of transparent $95 \mathrm{SiO}_{2}-5 \mathrm{LaF}_{3}$ bulk GC, co-doped and tri-doped with $\mathrm{Ln}^{3+}$ ions. Good UC properties after excitation at $\sim 980 \mathrm{~nm}$ were observed due to the interionic distance reduction between $\mathrm{Ln}^{3+}$ ions, as a consequence of their incorporation into the NCs. Moreover, by increasing the pump power the emitting color was tuned, obtaining white light generation with potential applications in multicolor solid-state displays and optical integrated devices (Figure 3). The incorporation of a high amount of dopant ions, around $75 \%$, in the precipitated $\mathrm{LaF}_{3} \mathrm{NCs}_{\text {was }}$ also reported by Velázquez et al. [54] for $\mathrm{Tb}^{3+}$-Dy ${ }^{3+}$ co-doped GCs, showing enhanced UV absorption band and allowing a shift in such emission to the Vis range.
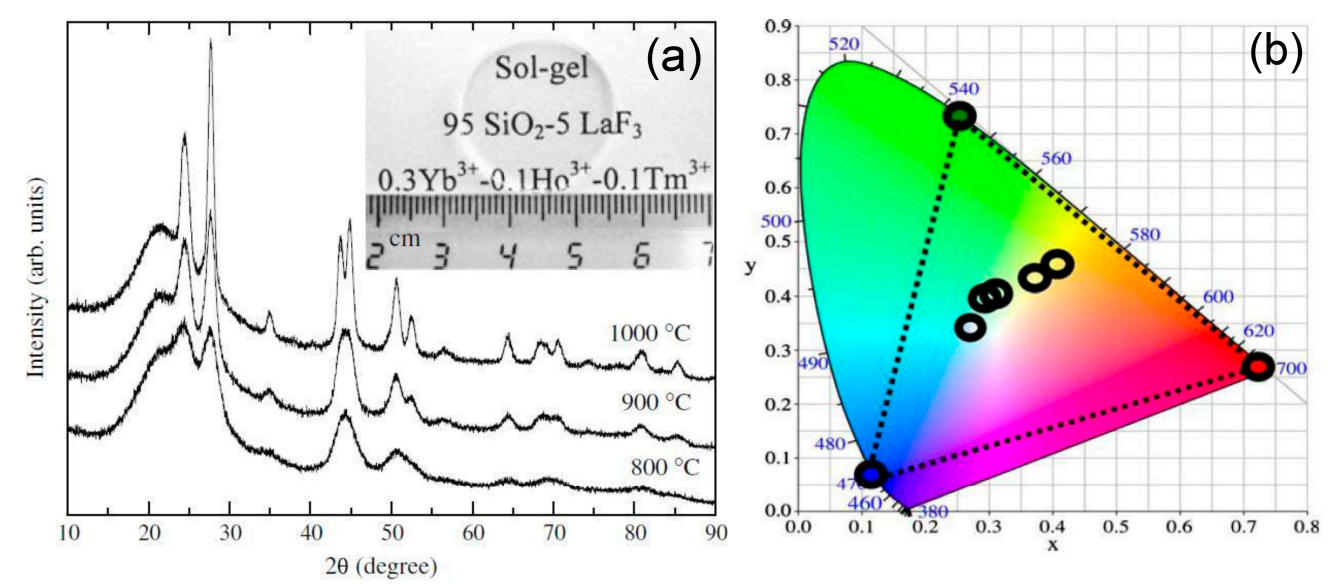

Figure 3. (a) XRD patterns of $95 \mathrm{SiO}_{2}-5 \mathrm{LaF}_{3} \mathrm{GCs}$ at different temperatures and (b) CIR standard chromaticity showing the up-conversion emission for GCs co-doped with $0.3 \mathrm{Yb}^{3+}, 0.1 \mathrm{Ho}^{3+}$ and $0.1 \mathrm{Tm}^{3+}[53]$. 
Other oxyfluoride GCs with special interest for photonics are those containing $\mathrm{YF}_{3} \mathrm{NCs}_{\text {. }}$ This crystal phase can act as a high quantum efficient host lattice for $\mathrm{Ln}^{3+}$ ions. Since 1998, when Dejneka published one of the first works on $\mathrm{Eu}^{3+}$-doped $\mathrm{YF}_{3}$ OxGCs by the MQ method [56], many authors started preparing materials containing this crystal phase. However, it was necessary to wait until 2006 to find one of the first works related to SG bulk materials based on the composition $90 \mathrm{SiO}_{2}-10 \mathrm{YF}_{3}$ [57]. The authors precipitated $\mathrm{YF}_{3}$ crystallites with sizes around $5 \mathrm{~nm}$ from the silica matrix when the xerogel was treated at $400{ }^{\circ} \mathrm{C}$. According to the authors, NCs aggregated to form larger particles. By increasing the temperature to $600{ }^{\circ} \mathrm{C}, \mathrm{YF}_{3} \mathrm{NC}$ tended to separate without changing their size, finally resulting in a homogeneous distribution in the glass matrix. They proposed that the precipitation of these crystals in the glassy phase induces high stress in the local region, which was reduced when increasing the treatment temperature due to the separation of the NCs from the agglomerates. Méndez-Ramos and co-workers published results based on the same $90 \mathrm{SiO}_{2}-10 \mathrm{YF}_{3}$ composition [58-60]. In these works, using $\mathrm{Ln}^{3+}$ as probe ions of the local environment, the authors found that a large fraction of optically active ions is efficiently embedded into the $\mathrm{YF}_{3} \mathrm{NCs}, 11 \mathrm{~nm}$ in size (Figure 4a). When the samples were co-doped with $\mathrm{Yb}^{3+}-\mathrm{Tm}^{3+}$, bright and efficient UC was achieved (Figure $4 \mathrm{~b}$ ), along with intense high-energy emissions in the UV range, due to rare 4- and 5-infrared photon processes. Moreover, co-doping with $\mathrm{Ho}^{3+}$ or $\mathrm{Er}^{3+}$ ions showed white light generation.
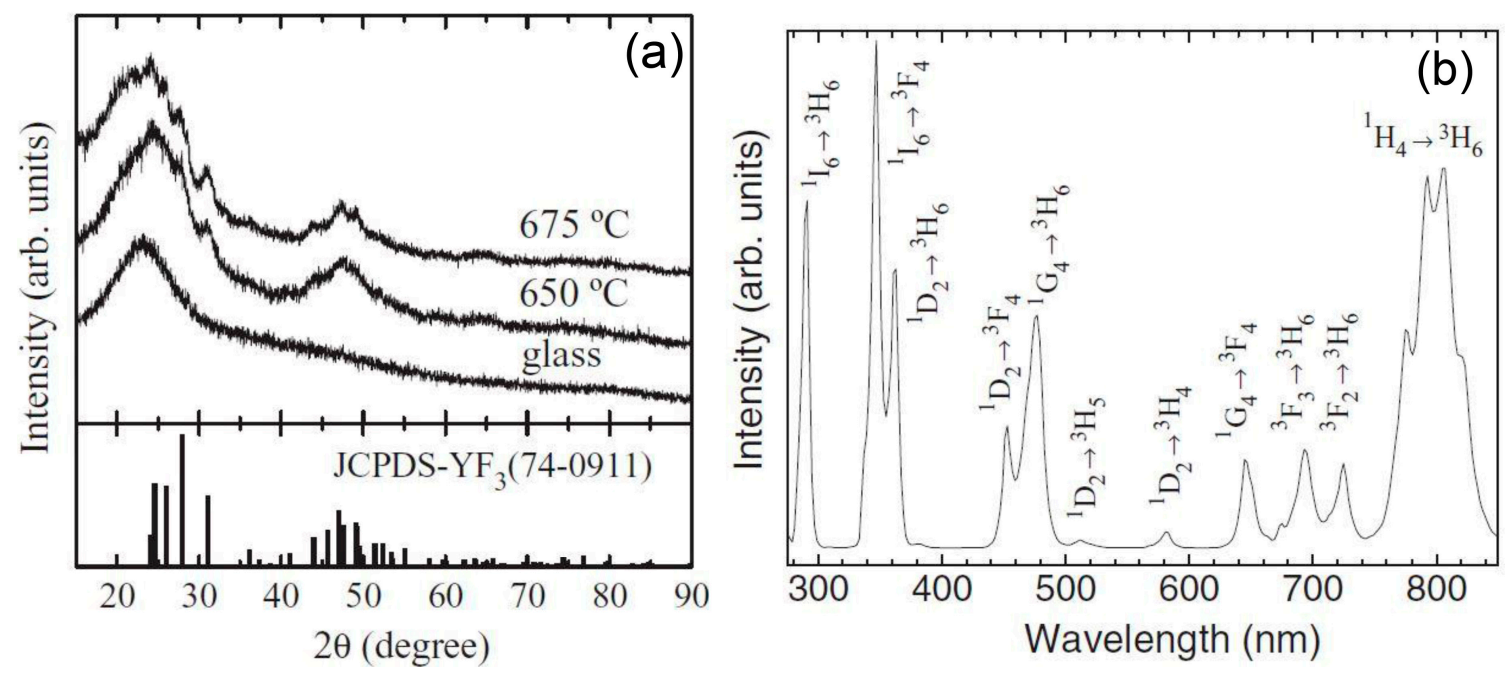

Figure 4. (a) $\mathrm{XRD}$ patterns of $90 \mathrm{SiO}_{2}-10 \mathrm{YF}_{3} \mathrm{Ln}^{3+}$-doped GCs heat treated at 650 and $675{ }^{\circ} \mathrm{C}$ together with the JCPDS-YF 3 and (b) Up-conversion emission spectrum of GCs co-doped with $1.5 \mathrm{Yb}^{3+}$ and $0.1 \mathrm{Tm}^{3+}$ heat-treated at $675^{\circ} \mathrm{C}[60]$.

Differently to $\mathrm{LaF}_{3}$ and $\mathrm{YF}_{3}, \mathrm{GdF}_{3}$ is considered a promising host because $\mathrm{Gd}^{3+}$ ions can act as $\mathrm{s}$ sensitizer for other $\mathrm{Ln}^{3+}$ ions and favor some ET processes [61], being suitable for application in Plasma Display Panels (PDPs) and mercury-free fluorescent lamps [62,63]. Only a few papers about SG GdF $3 \mathrm{OxGCs}$ have been published, with the nominal crystal phase content being less than $10 \mathrm{~mol}$ $\%$. Fuhijara et al. reported the synthesis of $90 \mathrm{SiO}_{2}-9 \mathrm{GdF}_{3}$ thin films doped with $1 \mathrm{~mol} \%$ of $\mathrm{EuF}_{3}$ [64]. Results confirmed that $\mathrm{GdF}_{3} \mathrm{NCs}, 5 \mathrm{~nm}$ in size, precipitated during heat treatment at 300 and $400{ }^{\circ} \mathrm{C}$, Figure 5, but GdOF NCs appeared when the temperature was increased to $500{ }^{\circ} \mathrm{C}$. More recently, Szpikowska-Sroka et al. studied the optical properties of $\mathrm{Eu}^{3+}$-doped $\mathrm{SiO}_{2}-\mathrm{GdF}_{3} \mathrm{GCs}$, with a very low composition of active media, around 3-6 mol \%, based on Fuhijara's synthesis [65-67]. The PL associated with $\mathrm{Eu}^{3+}$ ions in $\mathrm{GdF}_{3}$ phase was more efficient due to the low phonon energy of the crystal phase. 


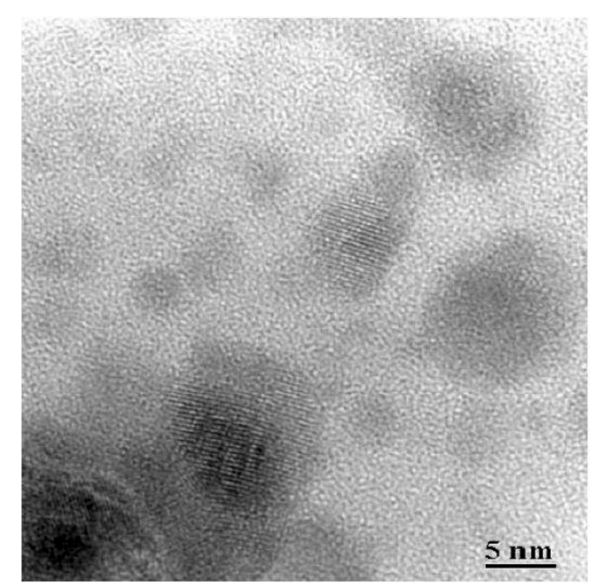

Figure 5. HRTEM image of $\mathrm{Eu}^{3+}$ doped $\mathrm{SiO}_{2}-\mathrm{GdF}_{3} \mathrm{GC}$ film heat $=$ treated at $400{ }^{\circ} \mathrm{C}$ [64].

\subsection{2. $\mathrm{M}_{1} \mathrm{M}_{2} \mathrm{~F}_{4} / \mathrm{F}_{5}$}

Complex fluoride structures became increasingly interesting in the last decade due to their good optical properties and capability of producing intense and efficient nonlinear optical processes as UC emission or other ET processes. In most cases phosphors were synthesized using SG, solvo-thermal, or co-precipitation methods and the final materials were used as powders. Other works concern the preparation of bulk materials and only few are about thin films.

Phosphors based on $\mathrm{NaYF}_{4}$ crystals have been known since the 1970s for their excellent UC properties when doped with $\mathrm{Yb}^{3+}$ and $\mathrm{Er}^{3+}$. In particular, $\mathrm{NaYF}_{4}$ phosphors' UC emission was found to be 4-5 times higher than that of $\mathrm{LaF}_{3}$ crystals [68]. Kramer et al. proposed a route to synthesize only pure hexagonal $\mathrm{NaYF}_{4}$ phosphors [69]. Moreover, transparent $\mathrm{NaYF}_{4}$ OxGCs bulk materials have been obtained by the MQ method, showing interesting PL properties even more efficient than those of powder phosphors [70,71].

However, the first work on $\mathrm{NaYF}_{4}$ OxGCs prepared by SG was published in 2009 by Yanes et al. [72]. $95 \mathrm{SiO}_{2}-5 \mathrm{NaYF}_{4}$ bulk materials doped with $0.1 \mathrm{Er}^{3+}$ and $0.3 \mathrm{Yb}^{3+}$ were obtained using acetates as precursor and the "Fujihara route". The ratio between red and green UC emission bands varied as a function of temperature of heat treatment and pump power resulting in color-tunable UC phosphors. The same authors also prepared $95 \mathrm{SiO}_{2}-5 \mathrm{NaYF}_{4}$ bulk materials doped with $0.1 \mathrm{Eu}^{3+}$ (mol \%) [73]. $\mathrm{NaYF}_{4}$ face-centered cubic NCs precipitated upon heat treatment between 550 and $650{ }^{\circ} \mathrm{C}$, their size increasing from 5 to $10 \mathrm{~nm}$ with the treatment temperature. PL measurements demonstrated the incorporation of $\mathrm{Eu}^{3+}$ into the $\mathrm{NCs}$, due to changes of emission bands using a selective excitation, together with an increase in the lifetime. The authors also reported bright white light generation achieved in similar materials tri-doped with $\mathrm{Yb}^{3+}-\mathrm{Ho}^{3+}-\mathrm{Tm}^{3+}[74]$ and $\mathrm{Yb}^{3+}-\mathrm{Er}^{3+}-\mathrm{Tm}^{3+}$ [75].

To the best of our knowledge, no $\mathrm{KYF}_{4}$ GC or composite materials prepared by MQ have been reported in the literature. The first GC was prepared by Mendez-Ramos et al. using the SG method and co-doping with $\mathrm{Yb}^{3+}-\mathrm{Er}^{3+}-\mathrm{Tm}^{3+}$ [76]. The processing method was the same used by the authors for other phases such as $\mathrm{NaYF}_{4}, \mathrm{LaF}_{3}$, etc. $\mathrm{K}, \mathrm{Y}$, and $\mathrm{Ln}^{3+}$ acetates were dissolved using ethanol, TFA, and water, while hydrolyzed TEOS were used as the $\mathrm{SiO}_{2}$ precursor, employing the well-known TEOS:EtOH:H $\mathrm{H}_{2} \mathrm{O}: \mathrm{CH}_{3} \mathrm{COOH}$ ratio 1:4:10:0.5. $\mathrm{KYF}_{4}$ crystals, $14-20 \mathrm{~nm}$ in size, were observed treating $95 \mathrm{SiO}_{2}-5 \mathrm{KYF}_{4}$ bulk materials between 650 and $700{ }^{\circ} \mathrm{C}$. Very well-resolved PL Stark components were observed for $\mathrm{Er}^{3+}$ and $\mathrm{Tm}^{3+}$ ions, indicating their incorporation into low-phonon $\mathrm{KYF}_{4}$ crystals (Figure 6). UC was obtained upon $\mathrm{Yb}^{3+}$ excitation at $980 \mathrm{~nm}$ and tunable emission was achieved depending on the dopant concentration and excitation power, allowing white light generation. The same composition was also studied by doping the system with other $\mathrm{Ln}^{3+}$ ions [77-79]. In all cases, the incorporation of $\mathrm{Ln}^{3+}$ ions into cubic $\mathrm{KYF}_{4}$ crystals was proved by PL measurements that showed defined Stark components, a better DC and UC process, and an increased lifetime as compared 
to emissions of $\mathrm{Ln}^{3+}$ ions remaining in the glass matrix. The possibility of obtaining both UC and DC simultaneously had interesting applications for a photovoltaic silicon solar cell and white light-emitting diodes.

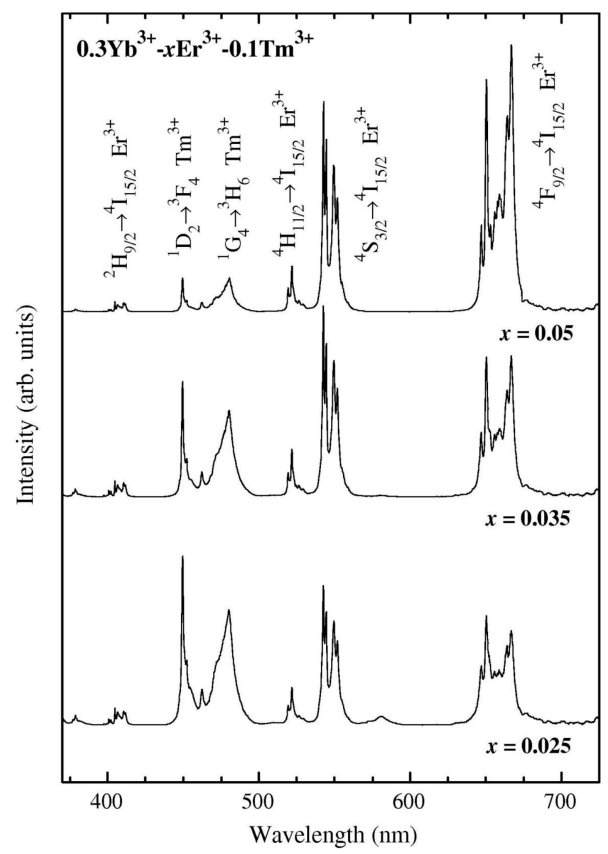

Figure 6. Up-conversion emission spectra of $95 \mathrm{SiO}_{2}-5 \mathrm{KYF}_{4}$ GCs co-doped with $\mathrm{Yb}^{3+}-\mathrm{Er}^{3+}-\mathrm{Tm}^{3+}$ heat-treated at $700{ }^{\circ} \mathrm{C}[76]$.

Despite some works based on $\mathrm{LiYF}_{4}$ OxGCs prepared by the MQ method appearing since 2009 [80], the first SG GCs containing $\mathrm{LiYF}_{4}$ crystals dates back to 2013 with the works of Kawamura et al. [81] and Secu et al. [82]. In both cases the authors used Fujihara's synthesis, and Li and F were added in excess to avoid losses due to evaporation and guarantee $\mathrm{LiYF}_{4}$ formation. In fact, a stoichiometric $\mathrm{Y}: \mathrm{Li}$ ratio favored the crystallization of $\mathrm{YF}_{3}$ instead of $\mathrm{LiYF}_{4}$. Gel powders were then treated between 500 and $600{ }^{\circ} \mathrm{C}$. Kawamura et al. obtained a mix of $\mathrm{LiYF}_{4}$ and $\mathrm{YF}_{3}$ phases when the Li:Y molar ratio was lower than 3, while only pure $\mathrm{LiYF}_{4}$ phase was produced using this ratio. By EDXS analysis, $\mathrm{Nd}^{3+}$ incorporation into the fluoride $\mathrm{NC}$ s was proven even though observable amounts of $\mathrm{F}, \mathrm{Nd}$, and $\mathrm{Y}$ were also detected in the glass matrix. UC spectra were obtained when exciting the samples at $800 \mathrm{~nm}$, showing crystal-like behavior. The $\mathrm{Nd}^{3+}$ lifetime in $\mathrm{LiYF}_{4}$ was longer than in $\mathrm{YF}_{3}$, suggesting a better $\mathrm{Nd}^{3+}$ distribution for the former. The same authors prepared the same materials with only LiYF crystals and treated the samples with $\mathrm{HF}$ to remove the $\mathrm{SiO}_{2}$ matrix [83]. However, relevant amounts of $\mathrm{O}$ and $\mathrm{Si}$ were detected after HF treatment and PL measurements did not show a significant difference after and before the HF treatment, thus ensuring the presence of $\mathrm{Nd}^{3+}$ ions in the fluoride $\mathrm{NCs}$.

Secu et al. [82,84] prepared $(100-\mathrm{x}) \mathrm{SiO}_{2}-\mathrm{xLiYF}_{4}$ GC powders doped with $\mathrm{Eu}^{3+}$ and $\mathrm{Er}^{3+}-\mathrm{Yb}^{3+}$ and compared the results for $\mathrm{LiYF}_{4}: \mathrm{Eu}^{3+}$ and $\mathrm{LiYF}_{4}: \mathrm{Er}^{3+}-\mathrm{Yb}^{3+}$ crystal pellets. As compared to an untreated xerogel, $\mathrm{Eu}^{3+}$-doped GC samples showed 7-8-fold stronger emission, a much longer lifetime of the ${ }^{5} \mathrm{D}_{0}-{ }^{7} \mathrm{~F}_{2}$ red emission $(613 \mathrm{~nm})$, and better resolved bands due to the Stark splitting and reduced inhomogeneous broadening typical of amorphous environments. Crystal pellets and GCs showed similar PL spectra and lifetimes. For $\mathrm{Er}^{3+}-\mathrm{Yb}^{3+}$-doped samples, UC emission was detected in both GCs and crystal pellets. A saturation effect of the red UC emission was observed for GC samples, associated with the high $\mathrm{Ln}^{3+}$ ions concentration, which caused a back-ET from $\mathrm{Er}^{3+}$ to $\mathrm{Yb}^{3+}$.

$\mathrm{BaYF}_{5}$ and $\mathrm{BaGdF}_{5}$ are other interesting crystal phases suitable for photonic applications. The first $95 \mathrm{SiO}_{2}-5 \mathrm{BaYF}_{5} \mathrm{GC}$ obtained by SG was prepared recently using $\mathrm{Eu}^{3+}$ and $\mathrm{Sm}^{3+}$ as dopants [85]. After heat treatment at $750{ }^{\circ} \mathrm{C}$ cubic $\mathrm{BaYF}_{5} \mathrm{NCs}, 11 \mathrm{~nm}$ in size, were detected by HRTEM and XRD. 


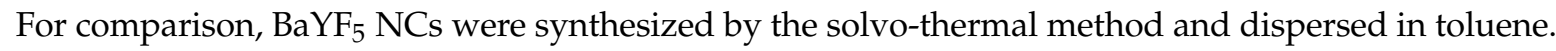
Similar PL features and lifetimes were obtained for the GC and the dispersed NCs. The same authors also prepared $95 \mathrm{SiO}_{2}-5 \mathrm{BaGd}_{(1-\mathrm{x})} \mathrm{RE}_{\mathrm{x}} \mathrm{F}_{5}\left(\mathrm{x}=0\right.$ or $0.02 \mathrm{~mol} \%$, where $\mathrm{RE}=\mathrm{Eu}^{3+}, \mathrm{Sm}^{3+}, \mathrm{Dy}^{3+}$ and $\mathrm{Tb}^{3+}$ ) GC [86]. After heat treatment at $650{ }^{\circ} \mathrm{C}, \mathrm{BaGdF}_{5} \mathrm{NCs}$, with a size around $10 \mathrm{~nm}$, precipitated in the $\mathrm{SiO}_{2}$ matrix (Figure 7). Upon $\mathrm{Gd}^{3+}$ excitation at $272 \mathrm{~nm}$ or $\mathrm{Eu}^{3+}$ direct excitation at $393 \mathrm{~nm}$, very similar $\mathrm{Eu}^{3+}$ emission spectra were obtained and the bands showed typical Stark components that were quite well resolved, thus confirming the incorporation of $\mathrm{Eu}^{3+}$ in the $\mathrm{BaGdF}_{5} \mathrm{NCs}$ and the ET from $\mathrm{Gd}^{3+}$ to $\mathrm{Eu}^{3+}$.

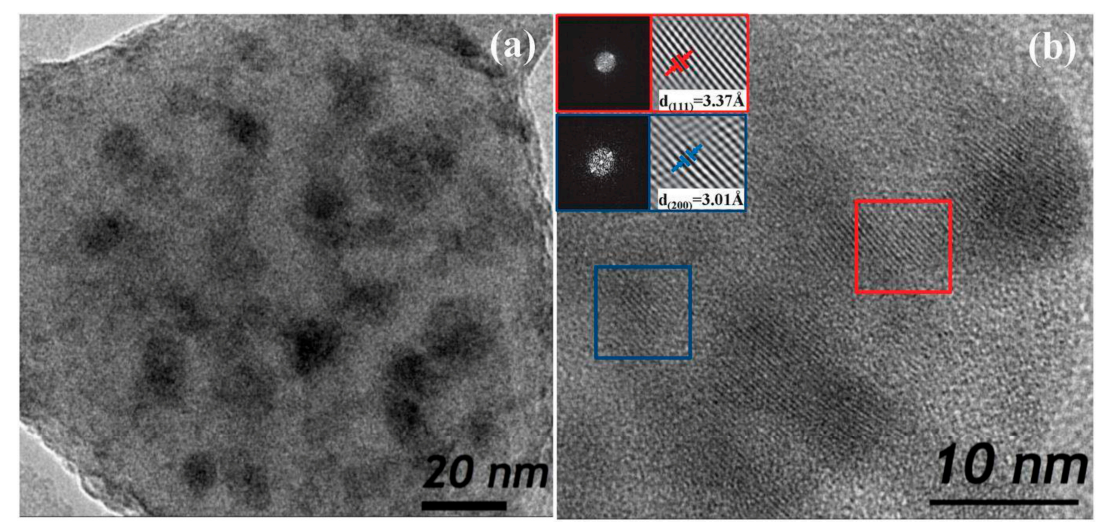

Figure 7. (a) TEM and (b) HRTEM images of $95 \mathrm{SiO}_{2}-5 \mathrm{BaGd}_{(1-\mathrm{x})} \mathrm{Eu}_{\mathrm{x}} \mathrm{F}_{5}$. Inset show power spectrum (FFT pattern) and filtered higher-contrasted red and blue square nanoparticles [86].

\subsection{Other Glass-Ceramics (Oxides and Oxyclorides)}

In this section we resume work concerning GCs based on different compositions containing oxide and oxychloride NCs. Oxide GCs have received great attention because some oxide phases present interesting properties. For example, it is worth citing $\mathrm{SnO}_{2}$, which is a wide gap n-type semiconductor with strong UV absorption (energy gap $\sim 3.6 \mathrm{eV}$ at $300 \mathrm{~K}$ ) and tunable emission spectra depending on the crystal size. In fact, $\mathrm{SnO}_{2}$ is known to act as a Quantum Dot (QD) when the crystal size is smaller than or comparable to the Bohr radius, thus showing properties between bulk semiconductor and discrete molecules that have many applications in several technological fields. Significant blue-energy shift of the intrinsic absorption edge can be obtained by strong quantum confinement of excitons inside the QDs $[87,88]$. The incorporation of $\mathrm{SnO}_{2} \mathrm{NCs}$ in an $\mathrm{SiO}_{2}$ glass matrix using SG dates back to 2002 with the works of Chiodini et al. [87] and Nogami et al. [89] Chiodini et al. reported on $98 \mathrm{SiO}_{2}-2 \mathrm{SnO}_{2}$ materials obtained by mixing TEOS and dibutyltin diacetate $\left(\mathrm{Sn}\left(\mathrm{CH}_{2} \mathrm{CH}_{2} \mathrm{CH}_{2} \mathrm{CH}_{3}\right)_{2}\left(\mathrm{OOCCH}_{3}\right)_{2}\right)$ in ethanol and using a TEOS: $\mathrm{H}_{2} \mathrm{O}$ molar ratio of 1:8. The samples were heated from 450 to $1050{ }^{\circ} \mathrm{C}$ in an $\mathrm{O}_{2}$ atmosphere and tetragonal $\mathrm{SnO}_{2} \mathrm{NCs}$ with a size of 1.5-2 nm were observed by HRTEM between 950 and $1050^{\circ} \mathrm{C}$. However, the NCs' size and distribution are strongly dependent on the atmosphere. NCs above $10 \mathrm{~nm}$ (clusters) were obtained for heat treatment at $1050{ }^{\circ} \mathrm{C}$ in reducing atmosphere. The near-UV absorption edge shifts to high energies by decreasing the synthesis temperature due to a decrease in the $\mathrm{SnO}_{2} \mathrm{NCs}$ ' size. The author concluded that a possible application of these materials could be as all-optical switching devices. The authors also reported that an increase in the $\mathrm{SnO}_{2}$ content up to $15 \mathrm{~mol} \%$ produces negative photorefractivity, activated by UV-Vis light [90]. A refractive index change of -4 and -6 , measured at $980 \mathrm{~nm}$, was obtained after sample irradiation at 266 and $532 \mathrm{~nm}$, respectively.

Nogami et al. prepared materials with compositions $(100-\mathrm{x}) \mathrm{SiO}_{2}-\mathrm{xSnO}_{2}(\mathrm{x}=1,3$ and $5 \mathrm{~mol} \%)$ doped with $1 \mathrm{~mol} \%$ of $\mathrm{Eu}_{2} \mathrm{O}_{3}$ [89]. They used TEOS as the $\mathrm{SiO}_{2}$ precursor and $\mathrm{SnCl}_{2} \cdot 2 \mathrm{H}_{2} \mathrm{O}$ together with $\mathrm{EuCl}_{3}$ as $\mathrm{SnO}_{2}$ and $\mathrm{Eu}^{3+}$ precursors, respectively. After a gelation period at room temperature for two weeks, bulk samples were treated from 500 to $1000{ }^{\circ} \mathrm{C}$ to ensure the densification of the glass matrix and allow $\mathrm{SnO}_{2} \mathrm{NCs}^{\prime}$ precipitation. For compositions containing 3 and $5 \mathrm{~mol} \%$ of $\mathrm{SnO}_{2}$, $\mathrm{NCs}$ with a size of 6.9 and $8.5 \mathrm{~nm}$ were obtained, while no NCs were observed for $99 \mathrm{SiO}_{2}-1 \mathrm{SnO}_{2}$ 
composition. Absorption measurements showed a blue shift of the band-tail with respect to $\mathrm{SnO}_{2}$ bulk sample. Higher blue-shift and energy gap were obtained when decreasing the $\mathrm{SnO}_{2}$ content, related to a smaller NCs size. PL showed that $\mathrm{Eu}^{3+}$ emission intensity increases proportionally to the third power of $\mathrm{SnO}_{2}$ concentration: $\mathrm{Eu}^{3+}$ emission in a $95 \mathrm{SiO}_{2}-5 \mathrm{SnO}_{2}$ sample was 150 times higher than in $99 \mathrm{SiO}_{2}-1 \mathrm{SnO}_{2}$. PL excitation spectra revealed an ET process between $\mathrm{Eu}^{3+}$ and $\mathrm{SnO}_{2} \mathrm{NCs}$, thus indicating the incorporation of $\mathrm{Eu}^{3+}$ in the crystal phase and making possible its emission upon $\mathrm{SnO}_{2}$ excitation. Other authors studied $(100-\mathrm{x}) \mathrm{SiO}_{2}-\mathrm{xSnO}_{2}(\mathrm{x}=1-10 \mathrm{~mol} \%)$ GCs doped with $\mathrm{Eu}^{3+}$ and $\mathrm{Eu}^{3+}-\mathrm{Tb}^{3+}$ following Nogami's synthesis [91-93]. By increasing the $\mathrm{SnO}_{2}$ content up to $10 \mathrm{~mol} \%$ (NCs size $\sim 5 \mathrm{~nm}$ ), a low quantum confinement effect was observed. Hence, most research was performed on GCs containing $5 \mathrm{~mol} \%$ of $\mathrm{SnO}_{2}$ and the optical characterization showed that in strong confinement conditions the energy gap has a high dependence on the NCs' size. Eu ${ }^{3+}$ ions incorporated in $\mathrm{SnO}_{2} \mathrm{NCs}$ were excited in the range 340-394 nm and, considering the variation of the band gap with the crystal size, the use of a certain excitation wavelength allowed for exciting only NCs with a defined crystal size, thus producing remarkable variation in the PL emission spectra. ET from $\mathrm{SnO}_{2} \mathrm{NCs}$ to $\mathrm{Tb}^{3+}$ ions was observed in $\mathrm{Eu}^{3+}-\mathrm{Tb}^{3+}$-doped GCs. It was observed that the ET depends on the crystal size, being favored for the smallest NCs. A relevant drawback related to $\mathrm{SnO}_{2} \mathrm{NCs}$ is the low solubility of $\mathrm{Ln}^{3+}$ limited to $\sim 0.05 \%$, the remaining ions being segregated at grain boundaries, probably in the form of $\mathrm{Ln}_{2} \mathrm{Sn}_{2} \mathrm{O}_{7}$ crystals [94]. To overcome this limitation, Van Tran et al. $[95,96$ ] prepared $\mathrm{SiO}_{2}-\mathrm{SnO}_{2}$ GCs with a maximum nominal NCs concentration of $20 \mathrm{~mol} \%$ to allow for higher $\mathrm{Ln}^{3+}$ amount incorporation in $\mathrm{SnO}_{2} \mathrm{NCs}$. The authors prepared $\mathrm{Er}^{3+}$-doped materials and PL measurements showed that an increase in $\mathrm{SnO}_{2}$ concentration promotes $\mathrm{Er}^{3+}$ ions' incorporation in $\mathrm{SnO}_{2} \mathrm{NCs}$.

Among $\mathrm{SiO}_{2}$ glass matrices containing oxide NCs, those containing $\mathrm{ZrO}_{2}$ crystals deserve special attention because $\mathrm{ZrO}_{2}$ is a pretty cheap material, transparent over a wide range of wavelengths: from $300 \mathrm{~nm}$ to $8 \mu \mathrm{m}$, it has quite low phonon energy $\sim 650 \mathrm{~cm}^{-1}$ and a high refractive index. Such properties have been exploited to develop $\mathrm{Ln}^{3+}$-activated planar waveguides at telecom wavelength $[97,98]$. $(100-\mathrm{x}) \mathrm{SiO}_{2}-\mathrm{xZrO}_{2}(\mathrm{x}=10-30 \mathrm{~mol} \%)$ homogenous and crack-free thin films doped with $\mathrm{Er}^{3+}$ were prepared following a synthesis route similar to $\mathrm{SnO}_{2}$, using TEOS and $\mathrm{ZrOCl}_{2} \cdot 8 \mathrm{H}_{2} \mathrm{O}$ as $\mathrm{SiO}_{2}$ and $\mathrm{ZrO}_{2}$ precursors, respectively. All waveguides showed the existence of one mode at $1550 \mathrm{~nm}$ with relatively low propagation losses; the refractive index increased from 1.492 to 1.609 for 10 and $30 \mathrm{~mol} \% \mathrm{ZrO}_{2}$, respectively. Narrow $\mathrm{Er}^{3+}$ emissions were observed in thin films with respect to glass materials, thus indicating $\mathrm{Er}^{3+}$ incorporation in $\mathrm{ZrO}_{2} \mathrm{NC}$. Suhaimi et al. [99] prepared several $(100-\mathrm{x}) \mathrm{SiO}_{2}-\mathrm{xZrO}_{2}$ compositions $(\mathrm{x}=30-70 \mathrm{~mol} \%)$ doped with $0.58 \mathrm{~mol} \% \mathrm{Er}^{3+}$. The refractive index at $1550 \mathrm{~nm}$ changed linearly from 1.6931 to 1.7334 by increasing $\mathrm{ZrO}_{2}$ content. Much higher PL emission of $\mathrm{Er}^{3+}$ at $568 \mathrm{~nm}$ was observed for films containing $70 \mathrm{~mol} \%$ of $\mathrm{ZrO}_{2}$, thus indicating that $\mathrm{ZrO}_{2}$ facilitates $\mathrm{Er}^{3+}$ to disperse homogeneously and the low phonon energy of the crystal phase reduces non-radiative losses. Other authors also studied $\mathrm{SiO}_{2}-\mathrm{ZrO}_{2}$ waveguides doped with $\mathrm{Er}^{3+}-\mathrm{Yb}^{3+}$ with $\mathrm{ZrO}_{2}$ contents up to a maximum of $25 \mathrm{~mol} \%$ [100]. Low roughness, a crack-free surface, and a high confinement coefficient were observed for all the compositions. $\mathrm{Er}^{3+}$ NIR PL was enhanced when the waveguide was co-doped with $\mathrm{Yb}^{3+}$, denoting an efficient ET between these ions. The authors considered the possibility of applying these materials as EDWA and WDM. Many GCs containing other oxide NCs have also been developed as waveguides [101-104].

To conclude this section, we mention the work of Secu et al. on oxychloride GCs [105]. $95 \mathrm{SiO}_{2}-5 \mathrm{LaOCl}$ GCs doped with $1 \mathrm{~mol} \% \mathrm{Eu}^{3+}$ were prepared following a similar synthesis to $\mathrm{LaF}_{3}$ GCs but replacing TFA with trichloacetic acid $\left(\mathrm{CCl}_{3} \mathrm{COOH}\right)$. $\mathrm{LaOCl}: \mathrm{Er}^{3+}$ pellets have also been prepared using a conventional solid state reaction between lanthanum oxide and ammonium chloride. DTA analysis showed that several exothermic peaks appear for measurements performed in air, but these peaks disappear completely for measurements in Ar. However, XRD confirmed the formation of $\mathrm{LaOCl} \mathrm{NCs,} 20-60 \mathrm{~nm}$ in size, during heat treatment at $450-750{ }^{\circ} \mathrm{C}$ in air. For heat treatment in Ar, smaller crystal size and fraction were obtained. Judd-Ofelt analysis along with PL measurements 
showed that, as the annealing temperature increases, a higher amount of $\mathrm{Eu}^{3+}$ ions is incorporated in $\mathrm{LaOCl} \mathrm{NCs,} \mathrm{thus} \mathrm{producing} \mathrm{a} \mathrm{better} \mathrm{resolved} \mathrm{Stark} \mathrm{component} \mathrm{and} \mathrm{a} \mathrm{much} \mathrm{longer} \mathrm{lifetime} \mathrm{with} \mathrm{respect}$ to xerogel. Similar results were obtained for $\mathrm{LaOCl}: \mathrm{Eu}^{3+}$ pellets, indicating the effective incorporation of $\mathrm{Eu}^{3+}$ in this crystal phase.

\subsection{Prospects and Perspectives}

In summary, most of the transparent SG OxGCs previously described are based on a unique synthesis developed by Fujihara et. al., using TMOS and/or TEOS as the $\mathrm{SiO}_{2}$ precursor, TFA as the fluorine source, and with an upper limit of nominal crystal phase around $10 \mathrm{~mol} \%$. The real crystal fraction in GCs was never estimated by a reliable method as Rietveld refinement and the few works that reported such information only used optical results to estimate the crystal content. Furthermore, many papers describe materials with $5 \mathrm{~mol} \%$ of nominal active phase, this being even less than that achievable by classical MQ and requiring an extremely long time for bulk sample preparation, from several weeks up to months. Moreover, quite high treatment temperatures, up to $1000{ }^{\circ} \mathrm{C}$, are used to crystallize the fluoride NCs when the crystallization of fluorides detected by DTA occurs at around $300{ }^{\circ} \mathrm{C}$. For all these reasons, research in the SG OxGCs field shows good and enhanced optical properties but no improvement of the synthesis, and no new processing methods have been reported in the literature since the first papers published 20 years ago.

In recent years, the GlaSS group of CSIC has been working on the optimization of the synthesis for significantly increasing the crystal content of SG OxGCs. In fact, it is worth noting that synthesis parameters such as molar ratios between precursors, temperature, and time of reaction are strictly dependent on the crystal phases and their content. Moreover, a unique synthesis, in general, is not suitable to obtain different compositions for the same crystal phase, and modifications of the synthesis are necessary to obtain novel materials. In addition, we partially replaced TEOS with methyltriethoxysilane (MTES) in the $\mathrm{SiO}_{2}$ sol synthesis, reducing the sintering temperature to $550{ }^{\circ} \mathrm{C}$ and making it possible to obtain enhanced optical properties without a need for much higher treatment temperatures.

\section{Experimental}

\subsection{Synthesis of $(100-x) \mathrm{SiO}_{2}-x \mathrm{LaF}_{3}$}

Our research started with $\mathrm{LaF}_{3} \mathrm{GC}$ films prepared by dip-coating. The precursors used were TEOS, $\mathrm{H}_{2} \mathrm{O}(0.1 \mathrm{M} \mathrm{HCl})$, EtOH, TFA, and $\mathrm{La}\left(\mathrm{CH}_{3} \mathrm{COO}\right)_{3}$. Dopants were added as acetates. A first $\mathrm{SiO}_{2}$ sol was prepared using a molar ratio 1TEOS:2 $\mathrm{H}_{2} \mathrm{O}(0.1 \mathrm{HCl}): 9.5 \mathrm{EtOH}$ stirred for $2 \mathrm{~h}$ at room temperature. Separately, $1 \mathrm{La}\left(\mathrm{CH}_{3} \mathrm{COO}\right)_{3}: 5 \mathrm{EtOH}: 5 \mathrm{TFA}: 4 \mathrm{H}_{2} \mathrm{O}$ were mixed and stirred for $2 \mathrm{~h}$ at $40^{\circ} \mathrm{C}$ in a glycerine bath. By mixing different volumes of $\mathrm{SiO}_{2}$ sol with the La solution, $90 \mathrm{SiO}_{2}-10 \mathrm{LaF}_{3}$ and $80 \mathrm{SiO}_{2}-20 \mathrm{LaF}_{3}$ compositions were obtained. To further increase the nominal $\mathrm{LaF}_{3}$ concentration to $30 \mathrm{~mol} \%$, the La solution was modified, adding more TFA (7 mol \%) to favor acetate dissolution. The last composition we obtained is $60 \mathrm{SiO}_{2}-40 \mathrm{LaF}_{3}$ and in this case a further increase of TFA up to $10 \mathrm{~mol} \%$ was necessary to obtain transparent thin films. Thin films were deposited by dip-coating on silica or Si substrates using a withdrawal rate of $20-45 \mathrm{~cm} / \mathrm{min}$. The thickness and refractive index of thin films were measured by a 2000 U ellipsometer (J.A. Woollam Co., Inc., Lincoln, NE, USA), using a Cauchy dispersion relation as a model.

Self-supported layers (or bulk-like samples) were also prepared with compositions $90 \mathrm{SiO}_{2}-10 \mathrm{LaF}_{3}$ and $80 \mathrm{SiO}_{2}-20 \mathrm{LaF}_{3}$ using the modified ratio of $\mathrm{SiO}_{2}$ sol 1TEOS:7.5 $\mathrm{H}_{2} \mathrm{O}(0.1 \mathrm{HCl}): 5 \mathrm{EtOH}$ while leaving unchanged the synthesis of La solution described before for thin films with the same composition. Samples were dried at $50{ }^{\circ} \mathrm{C}$ over two days and then the covering was removed, letting the solvent evaporate for seven days.

A further modification to obtain higher thickness of thin films and improve the mechanical resistance of self-supported layers was to partially replace TEOS with MTES in the ratio 
40TEOS:60MTES [106]. A modification of the molar ratios was necessary for thin film preparation to obtain the highest film thickness along with good sol stability. In particular, for thin films the $\mathrm{SiO}_{2}$ sol was prepared using 0.4TEOS:0.6MTES: $1 \mathrm{H}_{2} \mathrm{O}(0.1 \mathrm{HCl}): 2.5 \mathrm{E} \mathrm{tOH}: 0.2 \mathrm{CH}_{3} \mathrm{COOH}$, while the La solution was left unchanged. For self-supported layers, the previous TEOS: $\mathrm{H}_{2} \mathrm{O}$ ratio was used, replacing TEOS with 0.4 TEOS + 0.6 MTES (mol \%) to maintain the same ratio of $\mathrm{SiO}_{2}$ precursor and $\mathrm{H}_{2} \mathrm{O}$, which is a crucial parameter for bulk-like samples.

\subsection{Synthesis of $(100-x) \mathrm{SiO}_{2}-x G d F_{3} / \mathrm{NaGdF}_{4}$}

$90 \mathrm{SiO}_{2}-10 \mathrm{GdF}_{3}$ and $80 \mathrm{SiO}_{2}-20 \mathrm{LaF}_{3}$ self-supported layers were also obtained following the two-step process and using the aforementioned TEOS:MTES ratio for $\mathrm{SiO}_{2}$ sol. In this case Gd solution, using $\mathrm{Gd}\left(\mathrm{CH}_{3} \mathrm{COO}\right)_{3}$ as precursor, was stirred for $24 \mathrm{~h}$ at $40{ }^{\circ} \mathrm{C}$ to obtain a homogeneous solution of the products, thus making possible the crystallization of $\mathrm{GdF}_{3}$.

Finally, we prepared for the first time $\mathrm{SiO}_{2}-\mathrm{NaGdF}_{4}$ materials as self-supported layers and thin films. $\mathrm{A} \mathrm{SiO}_{2}$ sol was prepared using only TEOS as the $\mathrm{SiO}_{2}$ precursor with the same ratios used for $\mathrm{SiO}_{2}-\mathrm{LaF}_{3}$ compositions. Then, $\mathrm{Na}\left(\mathrm{CH}_{3} \mathrm{COO}\right), \mathrm{Gd}\left(\mathrm{CH}_{3} \mathrm{COO}\right)_{3}, \mathrm{EtOH}$, TFA, and $\mathrm{H}_{2} \mathrm{O}$ were mixed using similar ratios of TFA and EtOH and trying several Na:Gd ratios (1.125-0.80):1. The solution was stirred $24 \mathrm{~h}$ at $40^{\circ} \mathrm{C}$ in a glycerin bath.

For all compositions, GCs were obtained after heat treatment at $550-750{ }^{\circ} \mathrm{C}$ from $1 \mathrm{~min}$ up to several hours using heating rates of $1-10^{\circ} \mathrm{C} / \mathrm{min}$. In all cases, thermal quenching in air was performed to obtain good crystallization of the samples.

\subsection{Thermal and Structural Characterization}

DTA was performed in air and argon (inert) atmosphere on small pieces of 1-1.25 mm in size, with heating rates $10-40{ }^{\circ} \mathrm{C}$ using SDT Q600 (TA Instruments, New Castle, DE, USA) equipment. Measurements were performed in the range $25-800{ }^{\circ} \mathrm{C}$ using $15-30 \mathrm{mg}$ of sample.

High-resolution XRD patterns were collected in the range $6-27^{\circ}$ at the synchrotron SpLine BM25B of the ESRF (European Synchrotron Radiation Facility, Grenoble, France) using a wavelength of $0.619 \AA$ and a step size of $0.02^{\circ}$.

HRTEM was performed using a JEOL 2100 microscope (Akishima, Tokyo, Japan). Samples were prepared using lacey formvar carbon film that had a small amount of scratched sample deposited on them.

Fourier Transform Infra-Red (FTIR) spectra in the range $2000-600 \mathrm{~cm}^{-1}$ were obtained, with a resolution of $4 \mathrm{~cm}^{-1}$, using a Perkin Elmer Spectrum 100 instrument (Waltham, MA, USA).

${ }^{19} \mathrm{~F}$ magic-angle spinning nuclear magnetic resonance $\left({ }^{19} \mathrm{~F}\right.$ MAS/NMR) spectra of xerogel and GCs were recorded using a NMR Spectrometer AVANCE II (BRUKER, Billerica, MA, USA) equipped with a 9.4 Tesla magnet $(400 \mathrm{MHz})$ and a $2.5 \mathrm{~mm}$ rotor spinning at $20 \mathrm{kHz}$.

X-ray Absorption Spectroscopy (XAS) was measured at the SpLine BM25A of the ESRF collecting the spectra in fluorescence mode using a 13-element $\mathrm{Si}(\mathrm{Li})$ solid-state detector with the sample surface placed at an angle of $45^{\circ}$ to the incident beam. Six scans were acquired to obtain an average spectrum. XAS data were processed using ATHENA software [107]. $\mathrm{Eu}_{2} \mathrm{O}_{3}$ and $\mathrm{EuF}_{3}$ crystal powders were also measured as reference materials to compare their spectra with those of $\mathrm{Eu}^{3+}$-doped xerogel and GC samples.

Photoluminescence measurements were recorded using a FS5 fluorescence spectrometer (Edinburgh Instruments Ltd., Livingston, UK) equipped with a $150 \mathrm{~W}$ Xenon lamp or Ti:sapphire ring laser $\left(0.4 \mathrm{~cm}^{-1}\right.$ linewidth $)$ in the $770-920 \mathrm{~nm}$ spectral range. The emission was detected by Hamamatsu H10330A-75 or Hamamatsu R928P photomultiplier (Hamamatsu City, Shizuoka, Japan).

Even though several compositions were prepared, most of the results shown in the next sections deal with $80 \mathrm{SiO}_{2}-20 \mathrm{LaF}_{3} / \mathrm{GdF}_{3} / \mathrm{NaGdF}_{4}$ compositions, which have been studied in detail in recent years, all containing $20 \%$ of fluoride phases, at least double that reported by other authors. 


\section{Results and Discussion}

\subsection{Materials}

Transparent and crack-free GC thin films were obtained for all compositions, even for those containing 30 or $40 \mathrm{~mol} \%$ of active phase. For single deposition at $30 \mathrm{~cm} / \mathrm{min}$ and heat treatment at $550{ }^{\circ} \mathrm{C}$ for $1 \mathrm{~h}$, thicknesses around $500 \mathrm{~nm}$ and $1 \mu \mathrm{m}$ were obtained for TEOS and TEOS/MTES compositions, respectively. Higher thicknesses up to $900 \mathrm{~nm}$ and $1.7 \mu \mathrm{m}$ were obtained for TEOS and TEOS/MTES, respectively, depositing two films or increasing the withdrawal rate. Hence, the addition of MTES in the $\mathrm{SiO}_{2}$ sol allows a notable increase of the thickness, thus making this precursor attractive for application where a thin film of $1 \mu \mathrm{m}$ or thicker is required. Transparent and high-quality films were obtained, as confirmed by a good agreement between ellipsometry measurements and fits.

Transparent and crack-free self-supported layers were also obtained after heat treatments. The addition of MTES allows increasing the heating rate up to $10^{\circ} \mathrm{C} / \mathrm{min}$ without the appearance of cracks.

\subsection{Thermal and Structural Characterization}

\subsection{1. $\mathrm{SiO}_{2}-\mathrm{LaF}_{3}$}

DTA measurements for $(100-x) \mathrm{SiO}_{2}-\mathrm{LaF}_{3}(\mathrm{x}=10-40 \mathrm{~mol} \%)$ bulk samples obtained drying thin films sols are shown in Figure 8a. The curves show a first endothermic peak with a weight loss (not shown) associated with $\mathrm{H}_{2} \mathrm{O}$ and other solvent removal. Such an endothermic process is much more intense for a composition with a higher amount of La. This could be associated with the increasing water content passing from $x=10$ to $x=40$.

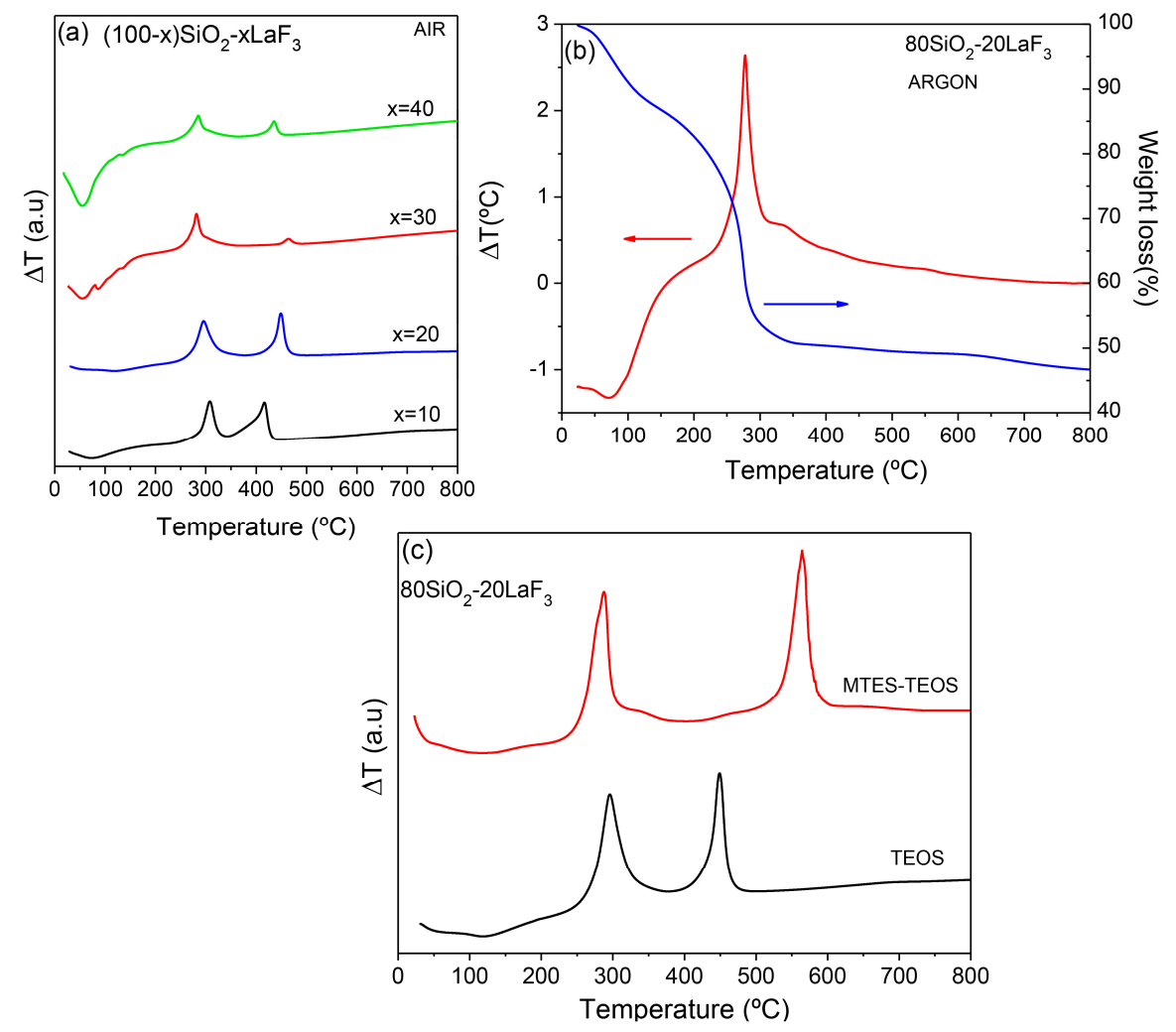

Figure 8. (a) DTA in air of $(100-x) \mathrm{SiO}_{2}-\mathrm{xLaF}_{3}(\mathrm{x}=10-40 \mathrm{~mol} \%)$ bulk samples prepared with TEOS; (b) DTA and TG in argon atmosphere of $80 \mathrm{SiO}_{2}-20 \mathrm{LaF}_{3}$ bulk samples prepared with TEOS; (c) DTA in air of $80 \mathrm{SiO}_{2}-20 \mathrm{LaF}_{3}$ bulk samples with TEOS and TEOS/MTES. All measurements were performed using a heating rate of $10^{\circ} \mathrm{C} / \mathrm{min}$. 
Then, a first exothermic peak appears around $300{ }^{\circ} \mathrm{C}$, together with a big mass loss that increases passing from $x=10$ to $x=40 \mathrm{~mol} \%$. The peak shifts towards lower temperatures when increasing the active phase content. As reported by other authors [43], such a peak is associated with the crystallization of $\mathrm{LaF}_{3}$, favored by increasing the La content. Such crystallization takes place after a chemical decomposition with gas release, which is responsible for the notable weight loss. The intensity of the endothermic and exothermic peaks is affected by the sample amount used for the analysis, and therefore it cannot be compared quantitatively. The second exothermic peak in the range $400-500{ }^{\circ} \mathrm{C}$ is assigned to organic combustion and was not detected in an argon atmosphere (Figure $8 b$ ). The effect of the $\mathrm{SiO}_{2}$ precursor on the DTA curve is shown in Figure $8 \mathrm{c}$ for $80 \mathrm{SiO}_{2}-20 \mathrm{LaF}_{3}$ samples prepared using TEOS and TEOS/MTES in the ratio 40:60 as $\mathrm{SiO}_{2}$ precursor. The crystallization peak appears centered around the same value, near $300{ }^{\circ} \mathrm{C}$, while the second exothermic peak is associated with organic combustion of different species. In fact, when MTES is used, $\mathrm{CH}_{3}$ groups are introduced in the system and released around $550-600{ }^{\circ} \mathrm{C}$. Such release is associated with a contraction of thin films and self-supported layers. Therefore, when MTES is used, treatment temperatures no higher than $550{ }^{\circ} \mathrm{C}$ should be used to avoid sample cracking. However, and concerning the crystallization mechanism, no relevant effects are introduced by the partial replacement of TEOS with MTES. The introduction of MTES improved the mechanical resistance during the treatment process and MTES bulk-like samples can be treated using a $10{ }^{\circ} \mathrm{C} / \mathrm{min}$ heating rate instead of $1-2{ }^{\circ} \mathrm{C} / \mathrm{min}$, as is commonly used for samples prepared using only TEOS. Moreover, MTES addition facilitates -OH group removal [108], without requiring extremely high treatment temperatures $\left(900-1000{ }^{\circ} \mathrm{C}\right)$.

The XRD of $80 \mathrm{SiO}_{2}-20 \mathrm{LaF}_{3}$ bulk sample prepared using TEOS/MTES and treated at $550{ }^{\circ} \mathrm{C}$ for $1 \mathrm{~min}$ is represented in Figure 9. Well-defined diffraction peaks are observed even for this fast treatment; the crystal size, estimated by Scherrer's equation, is around $8.5 \mathrm{~nm}$. No relevant $\mathrm{SiO}_{2}$ amorphous pattern is observed, different to the XRD results obtained by other authors [50-55,57], indicating a relevant increase of fluoride crystal fraction. Dopant incorporation, such as $\mathrm{Er}^{3+}$, was confirmed by an appreciable shift of the diffraction peaks towards higher angles, associated with a shrinking of the unit cell due to the lower size of $\mathrm{Er}^{3+}$ with respect to $\mathrm{La}^{3+}$ [109]. By Rietveld refinement (not shown), we obtained a $\mathrm{LaF}_{3}$ crystal fraction of $18 \mathrm{wt} \%$, which is, to the best of our knowledge, the highest value of fluoride concentration ever reported in OxGCs. The crystallization mechanism of $\mathrm{LaF}_{3}$ in $\mathrm{SG} \mathrm{OxGCs}$ has been studied in a previous paper [91]. It was shown that the $\mathrm{LaF}_{3}$ crystallization mechanism is very different to that for MQ GCs. In fact, for MQ GC a diffusion-controlled process is responsible for the crystallization of $\mathrm{LaF}_{3}$ and many other fluoride phases; phase separation acts as a precursor for crystallization. On the contrary, $\mathrm{LaF}_{3}$ crystallization in SG OxGCs is not a diffusion-controlled process but consists of a fast crystal precipitation taking place after a chemical decomposition. It was observed that $\mathrm{LaF}_{3} \mathrm{NCs}$ are not stable for heat treatment at crystallization or higher temperatures and amorphization was observed for a long treatment time $(5-80 \mathrm{~h})$ at $550{ }^{\circ} \mathrm{C}$.

HRTEM micrographs of $80 \mathrm{SiO}_{2}-20 \mathrm{LaF}_{3}$ thin films and self-supported layers treated at $550{ }^{\circ} \mathrm{C}$ for $1 \mathrm{~min}$ are shown in Figure 10a,b, respectively. Very small $\mathrm{LaF}_{3} \mathrm{NCs}$ around $2-3 \mathrm{~nm}$ are observed in thin film samples, as confirmed by the crystal size distribution shown in the inset. For self-supported layers the crystal size is much bigger, around $8 \mathrm{~nm}$, in agreement with the XRD results in Figure 3 . In both cases homogeneously distributed NCs are observed, without the formation of clusters, even for such a fast heat treatment at $550{ }^{\circ} \mathrm{C}$ for $1 \mathrm{~min}$.

NMR spectra of SG OxGCs are rarely encountered in the literature but the information that can be extracted is of relevant importance. In particular, ${ }^{19} \mathrm{~F}$ NMR spectra allow for obtaining evidence about fluorine surrounding in the xerogel and how it changes after the crystallization process. Figure 11 shows ${ }^{19} \mathrm{~F}$ MAS NMR of $80 \mathrm{SiO}_{2}-20 \mathrm{LaF}_{3}$ xerogel and GC treated at $550{ }^{\circ} \mathrm{C}$ for $1 \mathrm{~min}$ [110]. The spectrum of polycrystalline $\mathrm{LaF}_{3}$ was also acquired for comparison. In the xerogel sample the fluorine surrounding is as in the precursor TFA acid and no bonding with $\mathrm{Si}$ is observed. After heat treatment at $550{ }^{\circ} \mathrm{C}$ for $1 \mathrm{~min}$, the spectrum of the GC sample is practically the same as that 
of the $\mathrm{LaF}_{3}$ polycrystalline powders. This further indicates that a chemical reaction accompanied by fast crystal precipitation is responsible for the $\mathrm{LaF}_{3} \mathrm{NCs}^{\prime}$ formation.

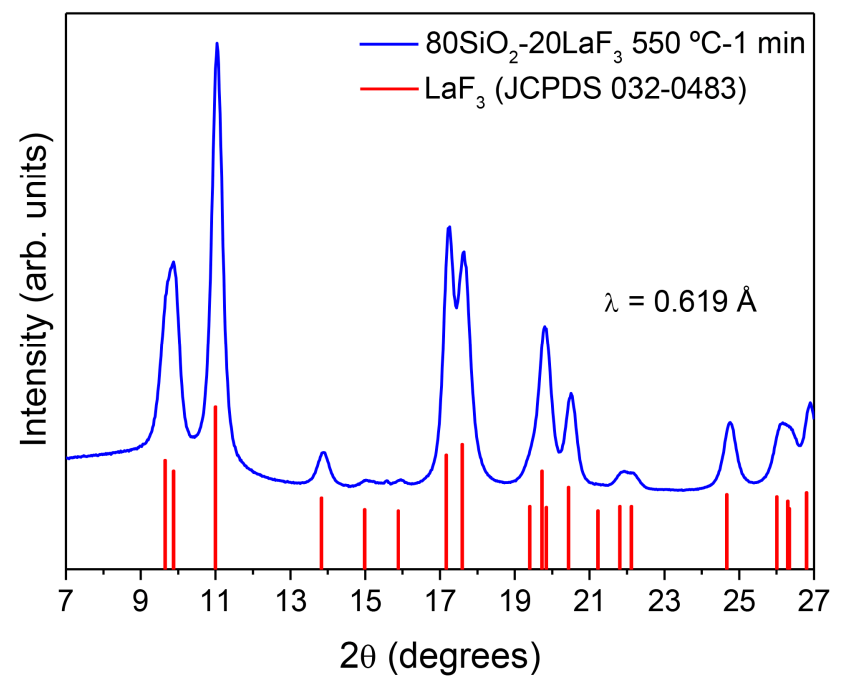

Figure 9. $\mathrm{XRD}$ of $80 \mathrm{SiO}_{2}-20 \mathrm{LaF}_{3} \mathrm{GC}$ treated at $550{ }^{\circ} \mathrm{C}$ for $1 \mathrm{~min}$ performed at the synchrotron SpLine $\mathrm{BM} 25 \mathrm{~B}$ of the ESRF.

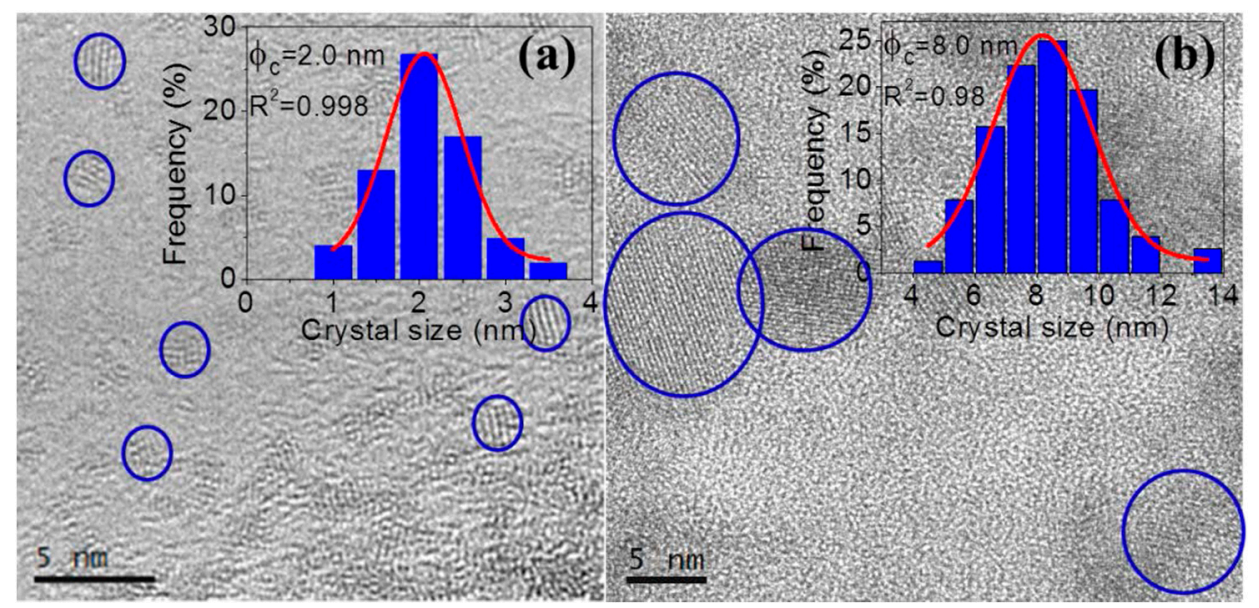

Figure 10. HRTEM of $80 \mathrm{SiO}_{2}-20 \mathrm{LaF}_{3}$ (a) thin film and (b) self-supported layer prepared using TEOS/MTES and treated at $550{ }^{\circ} \mathrm{C}$ for $1 \mathrm{~min}$. The corresponding crystal size distributions are also shown.

These results are further confirmed by FTIR spectra of $80 \mathrm{SiO}_{2}-20 \mathrm{LaF}_{3}$ xerogel and GCs treated at $550{ }^{\circ} \mathrm{C}$ for $1 \mathrm{~min}$ and $1 \mathrm{~h}$, as shown in Figure 12 [110]. In the xerogel, the bands centered at 1680 and $1650 \mathrm{~cm}^{-1}$ are associated with $\mathrm{H}-\mathrm{O}-\mathrm{H}$ bending and $\mathrm{C}=\mathrm{O}$ stretching vibrations, respectively. In the range $1500-1400 \mathrm{~cm}^{-1}$ several absorption bands appear and are assigned to TFA, acetates, and/or derived ions [43]. A C-F stretching band is also identified between 1400 and $1000 \mathrm{~cm}^{-1}$. All of these bands disappear in the GC sample, accompanied by $\mathrm{LaF}_{3} \mathrm{NCs}^{\prime}$ precipitation. In the GC the bands in the range $1100-800 \mathrm{~cm}^{-1}$ are associated with Si-O-Si asymmetric and symmetric stretching vibrations of $\left[\mathrm{SiO}_{4}\right]$ units. A small band at $1279 \mathrm{~cm}^{-1}$, also present in the xerogel sample but much more intense, is assigned to $\mathrm{C}-\mathrm{O}$ vibration and due to incompletely removed organic compounds. Such a band disappears over longer treatment times at $550{ }^{\circ} \mathrm{C}$. 


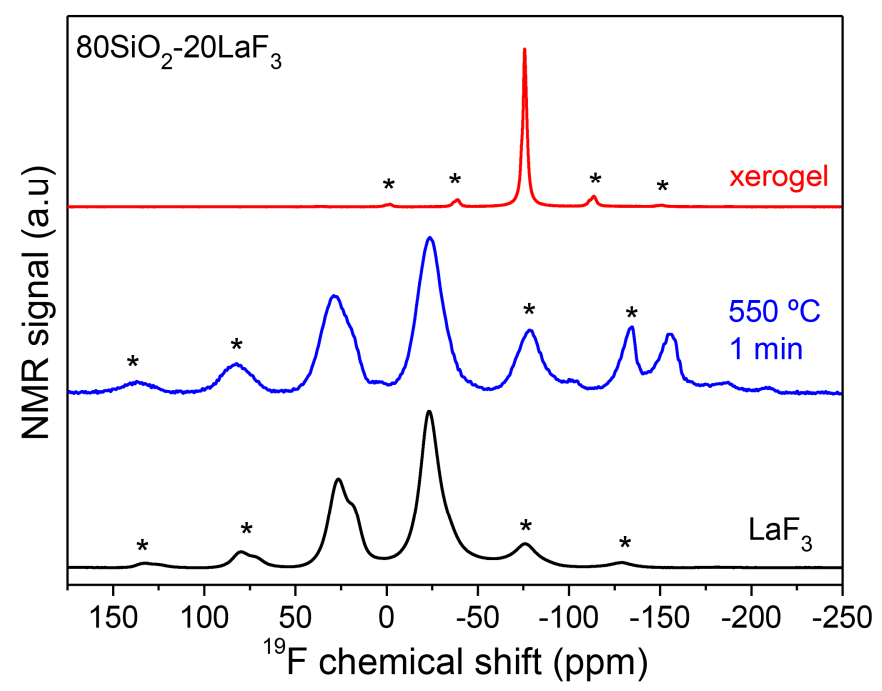

Figure 11. ${ }^{19} \mathrm{~F}$ MAS-NMR spectra of $80 \mathrm{SiO}_{2}-20 \mathrm{LaF}_{3}$ xerogel and GC treated at $550{ }^{\circ} \mathrm{C}$ for $1 \mathrm{~min}$. The spectrum of pure $\mathrm{LaF}_{3}$ crystal powder is also given for comparison. Stars indicate spinning sidebands.

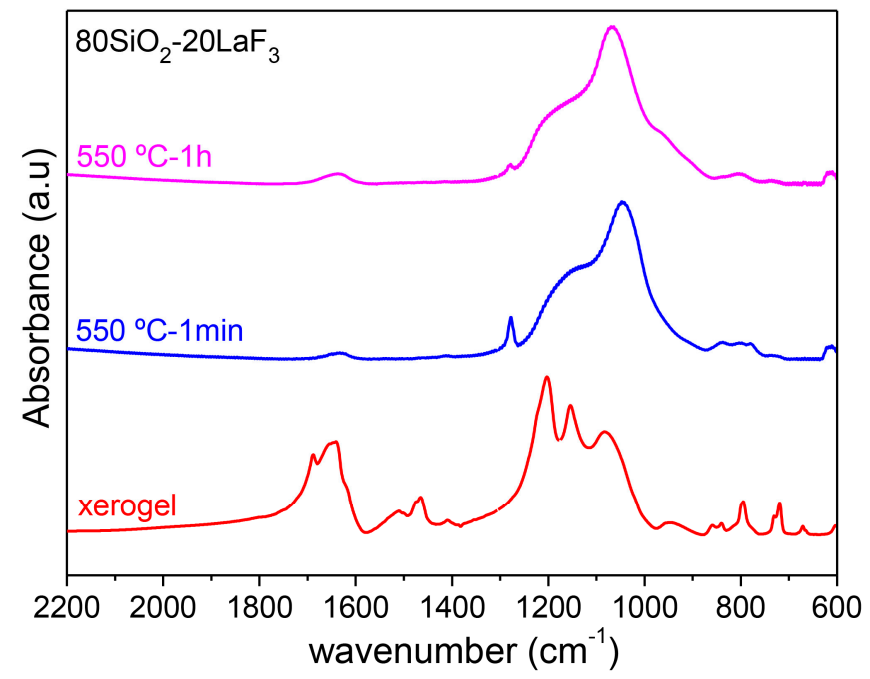

Figure 12. FTIR of $80 \mathrm{SiO}_{2}-20 \mathrm{LaF}_{3}$ xerogel and GC self-supported layer treated at $550{ }^{\circ} \mathrm{C}$ for $1 \mathrm{~min}$ and $1 \mathrm{~h}$.

Photoluminescence (PL) measurements are of great importance in most papers about SG OxGCs; in particular, enhanced properties are obtained when dopants are embedded into the fluoride NCs with low phonon energy. As an example, low-temperature (9 K) PL emission and excitation spectra of $80 \mathrm{SiO}_{2}-20 \mathrm{LaF}_{3}$ xerogel and GC treated at $650{ }^{\circ} \mathrm{C}$ for $3 \mathrm{~h}$ and doped with $0.5 \mathrm{Nd}^{3+}$ are shown in Figure 13 [111]. Both the emission and excitation spectra of the xerogel show broad and less structured bands, indicating a predominant amorphous environment for $\mathrm{Nd}^{3+}$ ions. Instead, for the GC sample sharp peaks and well-resolved Stark components are observed and associated with $\mathrm{Nd}^{3+}$ emission in $\mathrm{LaF}_{3} \mathrm{NCs}$. Similar features are observed for the excitation spectrum, where well-resolved peaks are observed for the ${ }^{4} \mathrm{I}_{9 / 2} \rightarrow{ }^{4} \mathrm{~F}_{5 / 2}$ band; moreover, the ${ }^{4} \mathrm{I}_{9 / 2} \rightarrow{ }^{4} \mathrm{~F}_{3 / 2}$ doublet narrows and splits into two main single components, as expected for a well-defined crystal field site. Therefore, $\mathrm{Nd}^{3+}$ incorporation into $\mathrm{LaF}_{3} \mathrm{NCs}$ was unambiguously confirmed. 

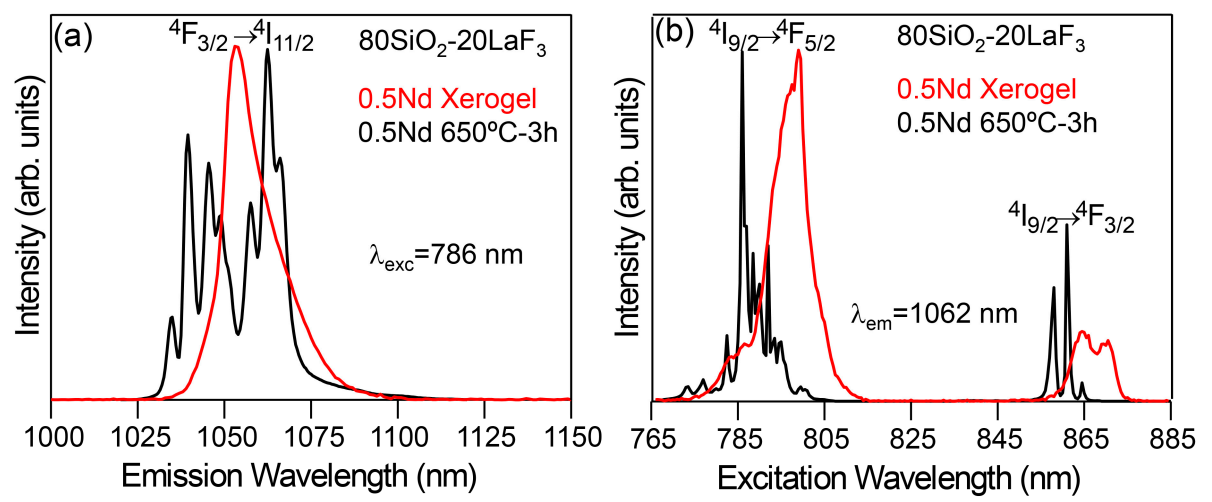

Figure 13. PL (a) emission and (b) excitation spectra of $80 \mathrm{SiO}_{2}-20 \mathrm{LaF}_{3}$ bulk xerogel and GC treated at $650{ }^{\circ} \mathrm{C}$ for $3 \mathrm{~h}$. All spectra were recorded at $9 \mathrm{~K}$.

\subsection{2. $\mathrm{SiO}_{2}-\mathrm{GdF}_{3} / \mathrm{NaGdF}_{4}$}

Figure 14 shows DTA curves of the $90 \mathrm{SiO}_{2}-10 \mathrm{NaGdF}_{4}$ bulk-like sample. The weight loss between 70 and $200{ }^{\circ} \mathrm{C}$, of less than $10 \%$, is ascribed to solvent removal. Then, as usually occurs for SG oxyfluoride compositions, a strong and sharp exothermic peak appears around $300{ }^{\circ} \mathrm{C}$ along with a mass loss of $30 \%$. Such an exothermic peak is associated with chemical decomposition with $\mathrm{NaGdF}_{4}$ precipitation, similar to that described by other authors for other fluoride crystal phases $[43,57,82]$. Further weight loss for heat treatment in the range $400-600{ }^{\circ} \mathrm{C}$ can be associated with the combustion of organic compounds. The same sample measured in an argon atmosphere showed similar characteristics; therefore, the exothermic peak is associated with $\mathrm{NaGdF}_{4}$ crystallization. Similar features are obtained for $\mathrm{SiO}_{2}-\mathrm{GdF}_{3}$ composition and described elsewhere [112].

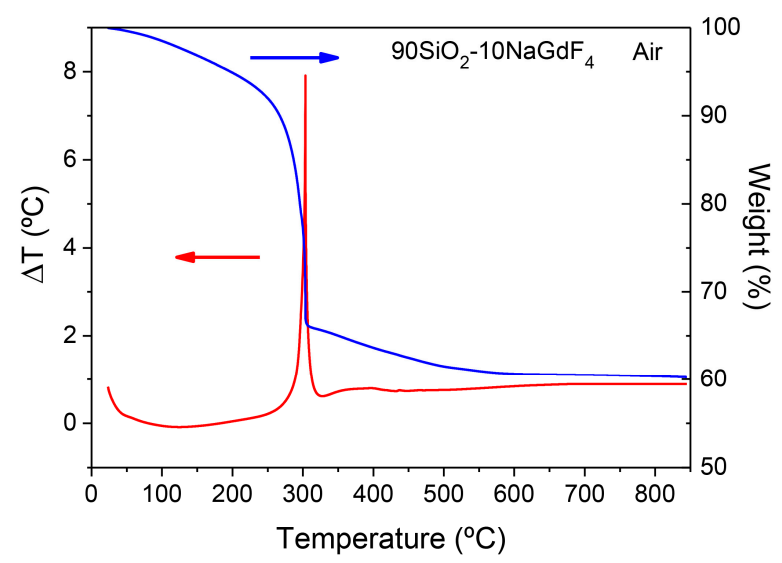

Figure 14. DTA (red) and TG (blue) curve of $90 \mathrm{SiO}_{2}-10 \mathrm{NaGdF}_{4}$ bulk sample acquired in air using a heating rate of $10^{\circ} \mathrm{C} / \mathrm{min}$.

Diffractograms of $(100-\mathrm{x}) \mathrm{SiO}_{2}-\mathrm{xGdF}_{3}(\mathrm{x}=10$ and $20 \mathrm{~mol} \%)$ treated at $550{ }^{\circ} \mathrm{C}$ for $1 \mathrm{~min}$ are shown in Figure 15. As observed, both phases of $\mathrm{GdF}_{3}$, orthorhombic and hexagonal, appear even for such fast heat treatment. It was shown that from $\mathrm{LaF}_{3}$ to $\mathrm{EuF}_{3}$, the hexagonal phase is preferred, while elements heavier than $\mathrm{Gd}$ are organized in orthorhombic structures [113]. Considering that Gd is right in the middle of a lanthanide series, it seems reasonable that a mixture of both phases appear. The relative intensity of hexagonal and orthorhombic structures is quite similar for all heat treatments, thus suggesting that there is no one preferential crystal structure but that both configurations coexist. Crystal size is around 8 and $9 \mathrm{~nm}$ for hexagonal and orthorhombic phases, respectively. Small changes in relative peak intensities can be associated with the deformation or preferential incorporation of $\mathrm{Eu}^{3+}$ ions at certain crystallographic sites. Moreover, the fact that similar sizes are obtained for 
both compositions suggests that NC formation is not related to the amount of the initial precursors, the mechanism being explained as fast crystal precipitation after a chemical reaction similar to that described by Fujihara for $\mathrm{LaF}_{3}$ [43]. However, the final crystal fraction should be affected by the initial content as observed for $\mathrm{LaF}_{3}$ compositions. Nevertheless, for $\mathrm{GdF}_{3}$ crystallization a quite different scenario is observed with respect to $\mathrm{LaF}_{3}$ crystallization, where an amorphization was observed over a long heat treatment time at $550{ }^{\circ} \mathrm{C}$. In fact, no changes in the crystal size are observed for treatment times up to $8 \mathrm{~h}$; the diffractograms of GCs treated for $1 \mathrm{~min}$ up to $8 \mathrm{~h}$ being practically the same. It seems that $\mathrm{GdF}_{3} \mathrm{NCs}$ are more stable against decomposition as opposed to $\mathrm{LaF}_{3}$ ones. Further work is still necessary to clarify this point.

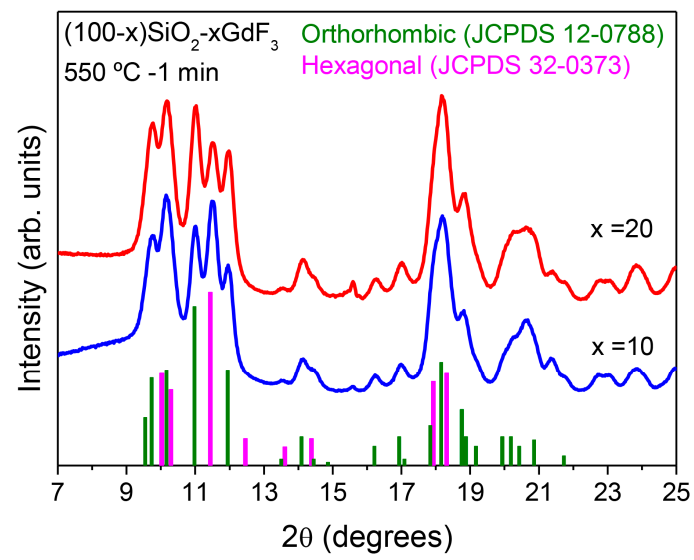

Figure 15. $\mathrm{XRD}$ of $(100-\mathrm{x}) \mathrm{SiO}_{2}-\mathrm{xGdF}_{3}(\mathrm{x}=10$ and $20 \mathrm{~mol} \%) \mathrm{GC}$ treated at $550{ }^{\circ} \mathrm{C}$ for $1 \mathrm{~min}$ performed at the synchrotron SpLine BM25 of the ESRF.

It is also worth noting that $\mathrm{SiO}_{2}$ precursors affect the final crystal phase and the crystal size. For example, for $80 \mathrm{SiO}_{2}-20 \mathrm{GdF}_{3}$ samples prepared using TEOS, only hexagonal crystals are detected but it was necessary to raise the temperature to $750{ }^{\circ} \mathrm{C}$ to obtain $\mathrm{GdF}_{3}$ crystals. Instead, for TEOS/MTES samples, even for treatment temperature as low as $550{ }^{\circ} \mathrm{C}$ for $1 \mathrm{~min}$, a good crystallization was obtained but in this case both a hexagonal and an orthorhombic phase appeared. Therefore, as was shown, the synthesis precursor and the different ratios between them can strongly affect the final crystal size, crystal fraction, and symmetry of the crystal phase. However, the influence of the $\mathrm{SiO}_{2}$ precursors and the synthesis route on the crystallization tendency of the systems has not yet been totally elucidated.

$\mathrm{XRD}$ of $80 \mathrm{SiO}_{2}-20 \mathrm{NaGdF}_{4}$ are shown in Figure 16. This is the first time that $\mathrm{NaGdF}_{4}$ crystals have been obtained in SG OxGCs. Diffractograms obtained for super-stoichiometric Na:Gd ratios caused the crystallization of silicates, along with $\mathrm{NaGdF}_{4}$. Therefore, precise control of the Na:Gd ratio was necessary to avoid the formation of silicates during heat treatment and obtain only the precipitation of fluoride NCs. It is known that $\mathrm{Na}^{+}$acts as a network modifier, producing more open glass structures. In fact, $\mathrm{Na}^{+}$ions can break $\mathrm{SiO}_{4}$ units, thus producing non-bridging oxygens with subsequent softening of the glass network. Hence, a sub-stoichiometric ratio Na:Gd 0.95:1 was necessary to ensure the complete reaction of $\mathrm{Na}$ with $\mathrm{Gd}$, avoiding the presence of free $\mathrm{Na}^{+}$ions. As observed in Figure 16, both $\alpha$ and $\beta-\mathrm{NaGdF}_{4}$ phases precipitated upon heat treatment at $600{ }^{\circ} \mathrm{C}$ for $1 \mathrm{~h}$ with a size of 4 and $13 \mathrm{~nm}$, respectively. However, for longer heat treatments, up to $120 \mathrm{~h}$, a relative decrease of the $\alpha$ phase, indicated by stars, is observed with respect to GC treated for only $1 \mathrm{~h}$. Moreover, sharper peaks are observed after increasing the treatment time, thus indicating the formation of bigger crystals (more than $30 \mathrm{~nm}$ in size). Such behavior is quite different to that described for $\mathrm{LaF}_{3}$, for which an increase of the treatment time increases neither the crystal size nor the crystal fraction. Therefore, it was suggested that $\mathrm{LaF}_{3}$ crystals formation occurs as a fast precipitation when certain energy is given to the system, instead being a diffusion-limited process, as proposed by other authors. However, for $\mathrm{NaGdF}_{4} \mathrm{OxGCs}$, a different crystallization mechanism occurs for polymorphous crystals; 
in particular, the addition of alkaline earth elements could be responsible for the better crystallinity obtained by increasing the treatment time. In fact, the time-dependent diffusion of $\mathrm{Na}^{+}$ions could be relevant to achieve better crystallization.

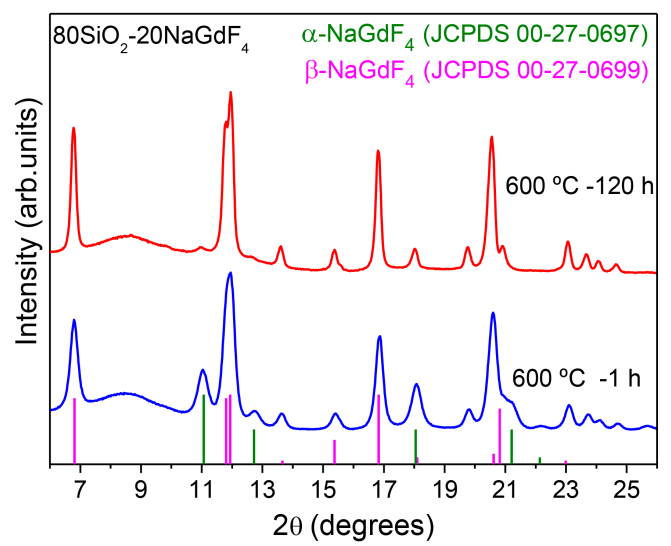

Figure 16. $\mathrm{XRD}$ of $80 \mathrm{SiO}_{2}-20 \mathrm{NaGdF}_{4}$ GC treated at $600{ }^{\circ} \mathrm{C}$ for 1 and $120 \mathrm{~h}$. The measurements were performed at the synchrotron SpLine BM25 of the ESRF.

Bartha et al. [114] studied $\mathrm{NaYF}_{4}$ phosphors and observed that for heat treatment at $300{ }^{\circ} \mathrm{C}$, both cubic and hexagonal $\mathrm{NaYF}_{4}$ micro crystals appeared. However, by increasing the treatment temperature to $400-600{ }^{\circ} \mathrm{C}$, only a pure hexagonal $\mathrm{NaYF}_{4}$ phase was observed. The authors explained such behavior as an autocatalytic process where the initial cubic $\mathrm{NaYF}_{4}$ phase played a catalytic role, causing its fast self-accelerated crystallization. The energy resulting from the disintegration process of the initial $\mathrm{NaYF}_{4}$ crystals contributed to the growth of hexagonal $\mathrm{NaYF}_{4}$ phase. This mechanism could also explain the crystallization of $\mathrm{NaGdF}_{4} \mathrm{NCs}$ in OxGCs but further investigation has still to be done.

Figure 17 shows a micrograph of $80 \mathrm{SiO}_{2}-20 \mathrm{GdF}_{3}$ self-supported layer doped with $0.5 \mathrm{Eu}^{3+}$ treated at $550{ }^{\circ} \mathrm{C}$ for $1 \mathrm{~min}$. As for $\mathrm{SiO}_{2}-\mathrm{LaF}_{3} \mathrm{GCs}$, homogeneously distributed NCs are observed and no agglomerates or clusters are observed, as suggested by other authors for $\mathrm{YF}_{3} \mathrm{NCs}$ [57]. By a detailed analysis of the microstructures, both hexagonal and orthorhombic crystals were detected according to JCPDS. EDXS of $\mathrm{Eu}^{3+}$ doped $80 \mathrm{SiO}_{2}-20 \mathrm{GdF}_{3} \mathrm{GC}$ treated at $550{ }^{\circ} \mathrm{C}$ for $1 \mathrm{~min}$ revealed that $\mathrm{Eu}^{3+}$ ions are mostly concentrated into $\mathrm{GdF}_{3} \mathrm{NCs}$. Therefore, dopant incorporation is very fast because even for a heat treatment as short as $1 \mathrm{~min}$, most $\mathrm{Eu}^{3+}$ ions are already embedded in the crystal phase. A better explanation of dopant incorporation is given later when the results about XAS will be discussed.

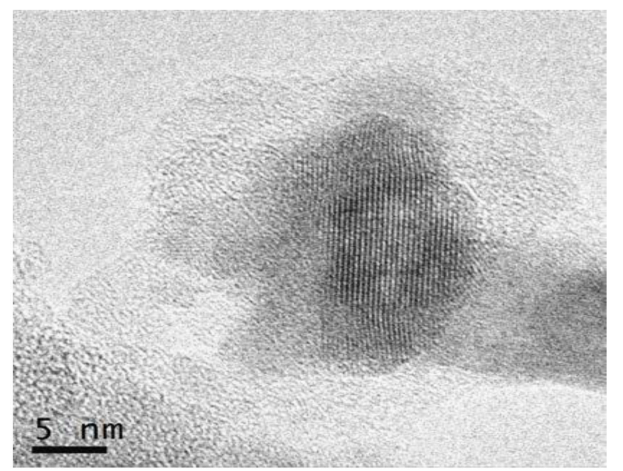

Figure 17. HRTEM of $80 \mathrm{SiO}_{2}-20 \mathrm{GdF}_{3}$ self-supported layer treated at $550{ }^{\circ} \mathrm{C}$ for $1 \mathrm{~min}$.

FTIR spectra of $80 \mathrm{SiO}_{2}-20 \mathrm{GdF}_{3}$ xerogel and GC treated at $550{ }^{\circ} \mathrm{C}$ for $1 \mathrm{~min}$ are shown in Figure 18 . Similar results are obtained with respect to the $80 \mathrm{SiO}_{2}-20 \mathrm{LaF}_{3}$ composition given in Figure 12 . For the xerogel sample TFA and acetate vibration bands are still present but disappear after heat treatment 
accompanied by $\mathrm{LaF}_{3}$ crystallization. Similar features are obtained for $\mathrm{SiO}_{2}-\mathrm{NaGdF}_{4}$ compositions, thus indicating that a chemical reaction followed by NC precipitation is a common feature of all the studied compositions. However, differences in crystallization behavior are also observed by XRD and therefore the crystal growth can be dependent on crystal phase and synthesis conditions.

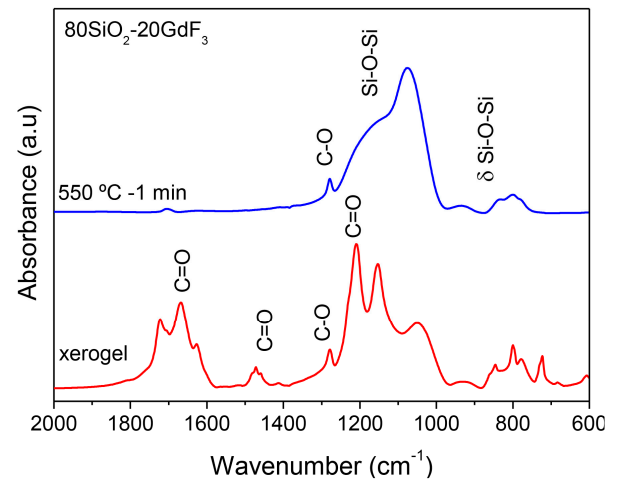

Figure 18. FTIR of $80 \mathrm{SiO}_{2}-20 \mathrm{GdF}_{3}$ xerogel and $\mathrm{GC}$ treated at $550{ }^{\circ} \mathrm{C}$ for $1 \mathrm{~min}$.

The last results that are shown in this paper deal with XAS spectra of $80 \mathrm{SiO}_{2}-20 \mathrm{GdF}_{3}$ materials doped with $\mathrm{Eu}^{3+}$. In particular, the spectra of the xerogel and GC sample are compared with the aim of gaining more insight into the $\mathrm{Eu}^{3+}$ environment. Indeed, better optical efficiencies are obtained when dopants are embedded into the NCs and knowledge of the real dopants fraction incorporated into the NCs is crucial to improve and optimize the luminescence emission of these materials. Even though a certain nominal dopant concentration is used, the real concentration into the fluoride NCs is rarely estimated, the only results being extrapolated from optical measurements [54]. Moreover, to estimate the effective concentration into the NCs, even with 10-20\% error, knowledge of the crystal fraction is necessary and such values are seldom or never reported for SG OxGCs. Last year our group started acquiring data to obtain this relevant information, but a lot of work has still to be done. However, some interesting conclusions can already be drawn from the results shown below. $\mathrm{Eu}_{2} \mathrm{O}_{3}$ and $\mathrm{EuF}_{3}$ spectra are shown in Figure 19a, together with their derivate curves in Figure 19b. The maximum of the derivate curves is 6977.9 and $6979.5 \mathrm{eV}$, for $\mathrm{Eu}_{2} \mathrm{O}_{3}$ and $\mathrm{ErF}_{3}$, respectively. A lower energy is associated with less electronegativity and a lower field strength of the $\mathrm{Ln}^{3+}$ ion [115]. The uncertainty of the energy values is around $0.8 \mathrm{eV}$. Therefore, it can be confirmed that the two maxima are well separated from each other. Figure $20 \mathrm{a}$,b show the results for a $80 \mathrm{SiO}_{2}-20 \mathrm{GdF}_{3}$ xerogel and GC samples treated at $550{ }^{\circ} \mathrm{C}$ for $1 \mathrm{~min}$ up to $8 \mathrm{~h}$. In all cases, the absorption maximum is centered at $\sim 6979 \mathrm{eV}$, practically the same value obtained for $\mathrm{EuF}_{3}$ reference. Hence, even though by these measurements it is not possible to distinguish between a crystalline or amorphous environment, the crucial point is that a fluorine-rich environment is observed for all GCs and even for the xerogel sample. Such behavior could be explained considering that $\mathrm{Eu}^{3+}$ ions are still coordinated to the surrounding TFA ions in the xerogel sample, and, after heat treatment, $\mathrm{GdF}_{3}$ crystals precipitate together with $\mathrm{Eu}^{3+}$ incorporation. These results are in agreement with $\mathrm{Eu}^{3+}$-rich $\mathrm{GdF}_{3} \mathrm{NCs}$ observed by EDXS for $80 \mathrm{SiO}_{2}-20 \mathrm{GdF}_{3} \mathrm{GC}$ treated at $550{ }^{\circ} \mathrm{C}$ for $1 \mathrm{~min}$.

Previous calculations performed for $80 \mathrm{SiO}_{2}-20 \mathrm{LaF}_{3}$ samples doped with $0.5 \mathrm{Er}^{3+}$ showed that almost $91 \%$ of $\mathrm{Er}^{3+}$ ions in GC samples are in a fluorine-rich environment, the effective concentration into the $\mathrm{LaF}_{3} \mathrm{NC}$ s thus being almost one order of magnitude higher than the nominal one. Similar results were obtained for MQ samples containing $\mathrm{LaF}_{3} \mathrm{NCs}$ and confirmed by PL results [116].

Finally, to conclude this section we show some optical results for $80 \mathrm{SiO}_{2}-20 \mathrm{GdF}_{3}$ self-supported layers doped with $0.5 \mathrm{Eu}^{3+}$. Photoluminescence measurements of $\mathrm{GC}$ treated at $550{ }^{\circ} \mathrm{C}$ for $1 \mathrm{~min}$ showed well-resolved structure together with a narrowing of the $\mathrm{Eu}^{3+}$ with respect to the xerogel sample (Figure 21). Moreover, the $R$ asymmetry ratio between the electric dipole transition $\left({ }^{5} \mathrm{D}_{0}{ }^{-}{ }^{7} \mathrm{~F}_{2}\right)$ and the magnetic dipole transition $\left({ }^{5} \mathrm{D}_{0^{-}}{ }^{7} \mathrm{~F}_{1}\right)$ is reduced in GCs, thus indicating that $\mathrm{Eu}^{3+}$ ions are 
incorporated in the $\mathrm{GdF}_{3}$ crystal phases. Moreover, the ET from $\mathrm{Gd}^{3+}$ to $\mathrm{Eu}^{3+}$ was observed in the GC sample and further supported by fluorescence decay lifetimes.
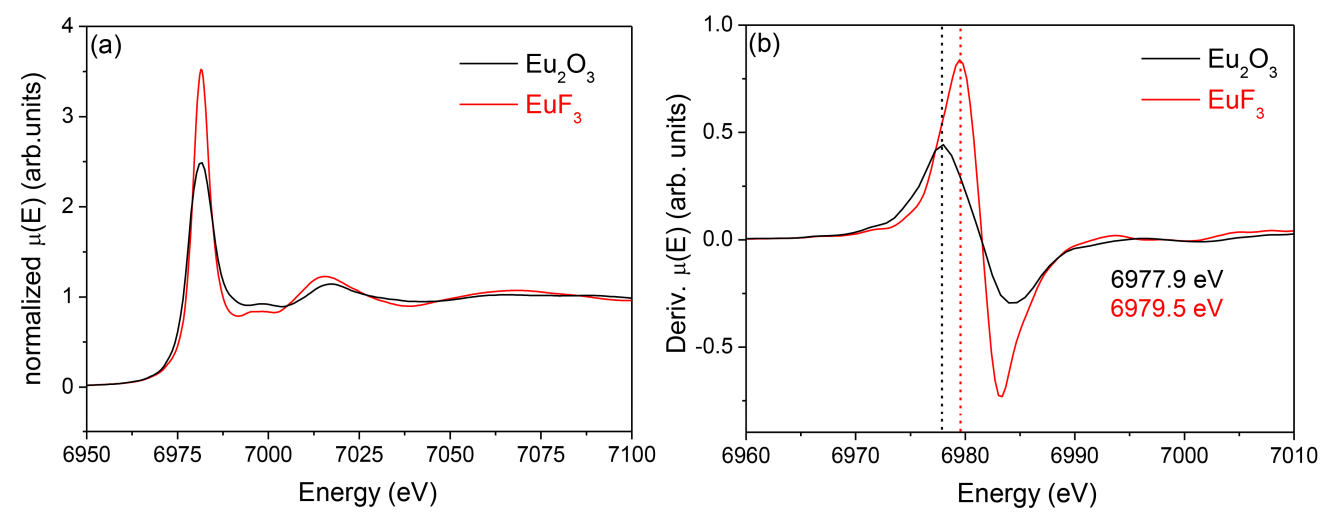

Figure 19. XAS (a) spectra and (b) derivate of $\mathrm{Eu}_{2} \mathrm{O}_{3}$ and $\mathrm{EuF}_{3}$ reference samples. The values shown in (b) refer to the maximum of the derivate curves.
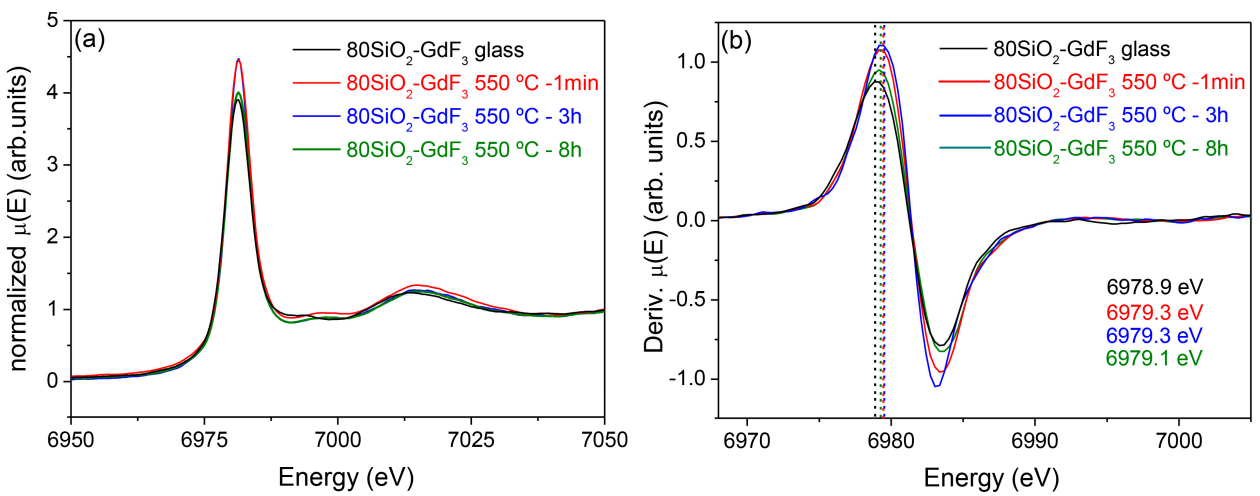

Figure 20. XAS (a) spectra and (b) derivate of $0.5 \mathrm{Eu}^{3+}$-doped $80 \mathrm{SiO}_{2}-20 \mathrm{LaF}_{3}$ xerogel and $\mathrm{GC}$ samples treated at $550{ }^{\circ} \mathrm{C}$ for $1 \mathrm{~min}$ up to $8 \mathrm{~h}$. The values shown in (b) refer to the maximum of the derivate curves.

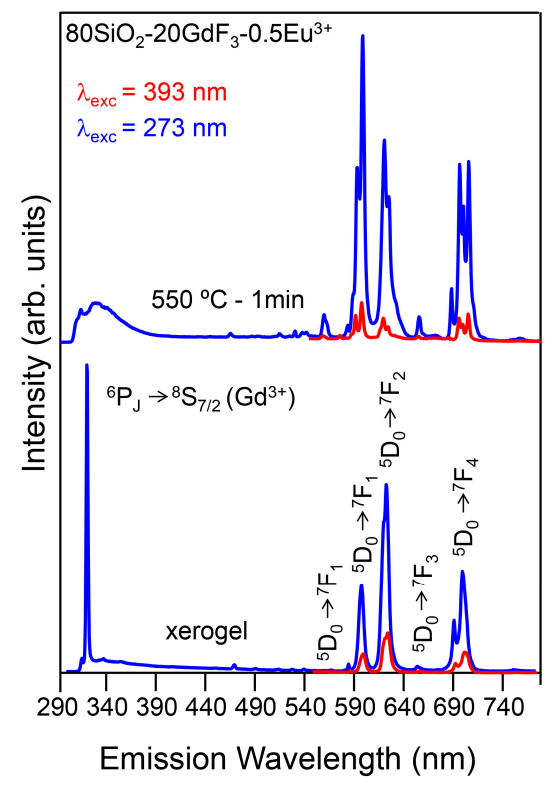

Figure 21. Emission spectra of $\mathrm{Eu}^{3+}$ and $\mathrm{Gd}^{3+}$ ions in xerogel (bottom) and GC (top) treated at $550{ }^{\circ} \mathrm{C}-1 \mathrm{~min}$ under excitation of $\mathrm{Eu}^{3+}$ at $393 \mathrm{~nm}$ (red spectra) and of $\mathrm{Gd}^{3+}$ at $273 \mathrm{~nm}$ (blue spectra). 


\section{Conclusions}

Different research groups have studied the preparation of transparent GC materials using the MQ process and suitable control of the synthesis and heat treatment conditions. However, SG appears as a promising alternative to obtain innovative GCs with high fluorine content and high homogeneity at a lower temperature.

Most of the materials studied by SG are related with compositions (100-x) $\mathrm{SiO}_{2}-\mathrm{x}$ $\mathrm{M}_{1} \mathrm{~F}_{2} / \mathrm{M}_{1} \mathrm{~F}_{3} / \mathrm{M}_{1} \mathrm{M}_{2} \mathrm{~F}_{4} / \mathrm{M}_{1} \mathrm{M}_{2} \mathrm{~F}_{5}$, containing a small nominal crystal fractions ( $\mathrm{x}=5-10 \mathrm{~mol} \%$ ), and are obtained using a similar synthesis procedure developed 20 years ago. Furthermore, the same $\mathrm{SiO}_{2}$ precursor, TEOS or TMOS, is used in most works, and the precursor ratio rarely changes with respect to the first papers.

There is scarce information about the structural characterization of bulk and thin films; typical characterization is performed by means of XRD, HRTEM, and FTIR. However, most of the authors never calculated the real crystal fraction. Just one or two papers estimated the real active crystal content and concluded that for a nominal composition of $5 \mathrm{~mol} \%$ of active phase, a $3 \mathrm{wt} \%$ of crystal phase is obtained after heat treatment. However, photoluminescence measurements of SG GCs showed very promising results. $\mathrm{Ln}^{3+}$ incorporation in fluoride NCs was demonstrated by several authors and produced an improvement in the optical properties (linear or non-) due to the low phonon energy of the crystal hosts, thus opening the way to use SG materials for photonic applications.

On the other side, our group introduced an important modification to the SG synthesis of OxGCs. First of all, $\mathrm{LaF}_{3}$ - and $\mathrm{GdF}_{3}$-based compositions with a much higher content of active phase (up to $40 \mathrm{~mol} \%$ ) have been prepared for the first time, together with $\mathrm{NaGdF}_{4}$ OxGCs. Moreover, new precursors and deep synthesis modification were performed by partial replacement of TEOS with MTES.

A chemical reaction followed by fast crystal precipitation was indicated as responsible for the crystallization mechanism of fluoride NCs, as opposed to conventional diffusion-controlled processes. $\mathrm{LaF}_{3} \mathrm{NCs}$ were demonstrated to be unstable with aging at crystallization or higher temperatures for a long treatment time, while for $\mathrm{NaGdF}_{4}$ an increase in the crystal size was observed when the treatment time increased. Therefore, the evolution and behavior of the NCs depend on the synthesis and the crystal phase.

Rietveld refinement confirmed that a crystal fraction $\sim 18 \mathrm{wt} \%$ is obtained for $80 \mathrm{SiO}_{2}-20 \mathrm{LaF}_{3} \mathrm{GC}$ treated at $550{ }^{\circ} \mathrm{C}$ for $1 \mathrm{~min}$, such a value being the highest reported to date for SG OxGCs.

HRTEM showed that homogeneously distributed fluoride NCs precipitate in the $\mathrm{SiO}_{2}$ glass matrix after fast heat treatment at $550{ }^{\circ} \mathrm{C}$ for 1 min using TEOS/MTES as $\mathrm{SiO}_{2}$ precursors. Moreover, EDXS confirmed dopants' incorporation in the fluoride NCs even after fast heat treatment at $550{ }^{\circ} \mathrm{C}$ for $1 \mathrm{~min}$, suggesting that dopant incorporation occurs along with NC precipitation. Such results were also confirmed by XAS measurements, revealing a fluorine-rich environment even in the xerogel sample.

Optical measurements unambiguously showed dopant incorporation in low-phonon-energy fluoride NCs. Well-resolved Stark components and crystal-like spectra were obtained for GC samples, resulting in much higher emission intensities and more efficient ET process with respect to xerogel samples.

Considering all the results published up to now and the benefits offered by the SG method, we think that transparent SG OxGCs materials can be considered of great interest and promising for several photonic applications, but improvement of synthesis and processing is still necessary. In this sense, we hope that this paper will be useful for researchers working in this field.

Acknowledgments: This work was supported by MINECO under projects MAT2013-48246-C2-1-P, MAT2013-48246-C2-2-P, and MAT2017-87035-C2-1-P/-2-P (AEI/FEDER, UE) and Basque Country Government IT-943-16 and PPG17/07. The authors are grateful for access to the Spanish Beamline (SpLine) at the ESRF facilities in Grenoble to perform experiments MA-3350 and 25-01-1014. Jose Joaquín Velázquez also acknowledges MINECO for Grant FPDI-2013-16895. 
Author Contributions: G.G., J.J.V., J.M., R.B., J.F., A.D. and Y.C. conceived and designed the experiments; G.G., J.J.V., R.B. and J.F. performed the experiments; G.G., J.J.V., R.B., J.F., A.D., Y.C. analyzed the data; G.G., J.J.V., J.M., R.B. and J.F. contributed reagents/materials/analysis tools; G.G., J.J.V., J.M., R.B., J.F., A.D. and Y.C. wrote the paper.

Conflicts of Interest: The authors declare no conflict of interest.

\section{References}

1. Feldmann, C.; Jüstel, T.; Ronda, C.R.; Schmidt, P.J. Inorganic luminescent materials: 100 years of research and application. Adv. Funct. Mater. 2003, 13, 511-516. [CrossRef]

2. George, N.C.; Denault, K.A.; Seshadri, R. Phosphors for solid-state white lightening. Annu. Rev. Mater. Res. 2013, 43, 481-501. [CrossRef]

3. Huang, X. Solid-state lighting: Red phosphor converts white LEDs. Nat. Photonics 2014, 8, 748-749. [CrossRef]

4. Huang, X.; Han, S.; Huang, W.; Liu, X. Enhancing solar cell efficiency: The search for luminescent materials as spectral converters. Chem. Soc. Rev. 2013, 42, 173-201. [CrossRef] [PubMed]

5. Eliseeva, S.V.; Bunzli, J.C.G. Lanthanide luminescence for functional materials and bio-sciences. Chem. Soc. Rev. 2010, 39, 189-227. [CrossRef] [PubMed]

6. Lee, H.U.; Park, S.Y.; Lee, S.C.; Choi, S.; Seo, S.; Kim, H.; Won, J.; Choi, K.; Kang, K.S.; Park, H.G.; et al. Black Phosphorus (BP) nanodots for potential biomedical applications. Small 2016, 12, 214-219. [CrossRef] [PubMed]

7. De Pablos-Martín, A.; Durán, A.; Pascual, M.J. Nanocrystallisation in oxyfluoride systems: Mechanisms of crystallisation and photonic properties. Int. Mater. Rev. 2012, 57, 165-186. [CrossRef]

8. Fedorov, P.P.; Luginina, A.A.; Popov, A.I. Transparent oxyfluoride glass ceramics. J. Fluor. Chem. 2015, 172, 22-50. [CrossRef]

9. De Pablos-Martín, A.; Ferrari, M.; Pascual, M.J.; Righini, G.C. Glass-ceramics: A class of nanostructured materials for photonics. La Rivista del Nuovo Cimento 2015, 38, 311-369. [CrossRef]

10. Wang, Y.; Ohwaki, J. New transparent vitroceramics codoped with $\mathrm{Er}^{3+}$ and $\mathrm{Yb}^{3+}$ for efficient frequency upconversion. Appl. Phys. Lett. 1993, 63, 3268-3270. [CrossRef]

11. Stevenson, A.J.; Serier-Brault, H.; Gredin, P.; Mortier, M. Fluoride materials for optical applications: Single crystals, ceramics, glasses, and glass-ceramics. J. Fluor. Chem. 2011, 132, 1165-1173. [CrossRef]

12. Lopez-Iscoa, P.; Salminen, T.; Hakkarainen, T.; Petit, L.; Janner, D.; Boetti, N.; Lastusaari, M.; Pugliese, D.; Paturi, P.; Milanese, D. Effect of partial crystallization on the structural and luminescence properties of $\mathrm{Er}^{3+}$-doped phosphate glasses. Materials 2017, 10, 473. [CrossRef] [PubMed]

13. Höland, W.; Beall, G. Glass-Ceramic Technology, 3rd ed.; The American ceramic society: Westerville, OH, USA, 2002; pp. 15-18.

14. Augustyn, E.; Żelechower, M.; Stróż, D.; Chrapoński, J. The microstructure of erbium-ytterbium co-doped oxyfluoride glass-ceramic optical fibers. Opt. Mater. 2012, 34, 944-950. [CrossRef]

15. Reben, M.; Dorosz, D.; Wasylak, J.; Burtan-Gwizdala, B.; Jaglarz, J.; Zontek, J. Nd ${ }^{3+}$-doped oxyfluoride glass ceramics optical fibre with $\mathrm{SrF}_{2}$ nanocrystals. Opt. Appl. 2012, 42, 353-364. [CrossRef]

16. Krishnaiah, K.V.; Ledemi, Y.; Genevois, C.; Veron, E.; Sauvage, X.; Morency, S.; Soares de Lima Filho, E.; Nemova, G.; Allix, M.; Messaddeq, Y. Ytterbium-doped oxyfluoride nano-glass-ceramic fibers for laser cooling. Opt. Mater. Express 2017, 7, 1980-1994. [CrossRef]

17. Gorni, G.; Balda, R.; Fernández, J.; Ipparraguirre, I.; Velázquez, J.J.; Castro, Y.; Chen, G.; Sundararayan, M.; Pascual, M.J.; Durán, A. Oxyfluoride glass-ceramic fibers doped with $\mathrm{Nd}^{3+}$ : Structural and optical characterization. CrystEngComm 2017, 19, 6620-6629. [CrossRef]

18. Roberts, R.B.; Tainsh, R.J.; White, G.K. Thermal properties of Zerodur at low temperatures. Cryogenics 1982, 22, 566-568. [CrossRef]

19. Owens, G.J.; Singh, R.K.; Foroutan, F.; Alqaysi, M.; Han, C.M.; Mahapatra, C.; Kim, H.W.; Knowles, J.C. Sol-gel based materials for biomedical applications. Prog. Mater. Sci. 2016, 77, 1-79. [CrossRef]

20. Rywak, A.A.; Burlitch, J.M. Sol-gel synthesis of nanocrystalline magnesium fluoride: Its use in the preparation of $\mathrm{MgF}_{2}$ films and $\mathrm{MgF}_{2}-\mathrm{SiO}_{2}$ composites. Chem. Mater. 1996, 8, 60-67. [CrossRef] 
21. Rywak, A.A.; Burlitch, J.M. The crystal chemistry and thermal stability of sol-gel prepared fluoride-substituted talc. Phys. Chem. Miner. 1996, 23, 418-431. [CrossRef]

22. Fujihara, S.; Tada, M.; Kimura, T. Preparation and characterization of $\mathrm{MgF}_{2}$ thin film by a trifluoroacetic acid method. Thin Solid Films 1997, 304, 252-255. [CrossRef]

23. Luo, W.; Wang, Y.; Bao, F.; Zhou, L.; Wang, X. Crystallization behavior of $\mathrm{PbF}_{2}-\mathrm{SiO}_{2}$ based bulk xerogels. J. Non-Cryst. Solids 2004, 347, 31-38. [CrossRef]

24. Del-Castillo, J.; Yanes, A.C.; Méndez-Ramos, J.; Tikhomirov, V.K.; Rodríguez, V.D. Structure and up-conversion luminescence in sol-gel derived $\mathrm{Er}^{3+}-\mathrm{Yb}^{3+}$ co-doped $\mathrm{SiO}_{2}: \mathrm{PbF}_{2}$ nano-glass-ceramics. Opt. Mater. 2009, 32, 104-107. [CrossRef]

25. Del-Castillo, J.; Yanes, A.C.; Méndez-Ramos, J.; Tikhomirov, V.K.; Moshchalkov, V.V.; Rodríguez, V.D. Sol-gel preparation and white up-conversion luminescence in rare-earth doped $\mathrm{PbF}_{2}$ nanocrystals dissolved in silica glass. J. Sol-Gel Sci. Technol. 2010, 53, 509-514. [CrossRef]

26. Szpikowska-Sroka, B.; Zur, L.; Czoik, R.; Goryczka, T.; Swinarew, A.S.; Żadło, M.; Pisarski, W.A. Long-lived emission from $\mathrm{Eu}^{3+}: \mathrm{PbF}_{2}$ nanocrystals distributed into sol-gel silica glass. J. Sol-Gel Sci. Technol. 2013, 68, 278-283. [CrossRef]

27. Szpikowska-Sroka, B.; Pawlik, N.; Zur, L.; Czoik, R.; Goryczka, T.M.; Pisarski, W.A. Effect of fluoride ions on the optical properties of $\mathrm{Eu}^{3+}: \mathrm{PbF}_{2}$ nanocrystals embedded into sol-gel host materials. Mater. Chem. Phys. 2016, 174, 138-142. [CrossRef]

28. Szpikowska-Sroka, B.; Pawlik, N.; Goryczka, T.; Pietrasik, E.; Bańczyk, M.; Pisarski, W.A. Lead fluoride $\beta-\mathrm{PbF}_{2}$ nanocrystals containing $\mathrm{Eu}^{3+}$ and $\mathrm{Tb}^{3+}$ ions embedded in sol-gel materials: Thermal, structural and optical investigations. Ceram. Int. 2017, 43, 8424-8432. [CrossRef]

29. Yu, Y.; Chen, D.; Wang, Y.; Luo, W.; Zheng, Y.; Cheng, Y.; Zhou, L. Structural evolution and its influence on luminescence of $\mathrm{SiO}_{2}-\mathrm{SrF}_{2}-\mathrm{ErF}_{3}$ glass ceramics prepared by sol-gel method. Mater. Chem. Phys. 2006, 100, 241-245. [CrossRef]

30. Yu, Y.; Wang, Y.; Chen, D.; Liu, F. Efficient upconversion luminescence of $\mathrm{Er}^{3+}: \mathrm{SrF}_{2}-\mathrm{SiO}_{2}-\mathrm{Al}_{2} \mathrm{O}_{3}$ sol-gel glass ceramics. Ceram. Int. 2008, 34, 2143-2146. [CrossRef]

31. Zhou, L.; Chen, D.; Luo, W.; Wang, Y.; Yu, Y.; Liu, F. Transparent glass ceramic containing $\operatorname{Er}^{3+}: \mathrm{CaF}_{2}$ nano-crystals prepared by sol-gel method. Mater. Lett. 2007, 61, 3988-3990. [CrossRef]

32. Georgescu, S.; Voiculescu, A.M.; Matei, C.; Secu, C.E.; Negre, R.F.; Secu, M. Ultraviolet and visible up-conversion luminescence of $\mathrm{Er}^{3+} / \mathrm{Yb}^{3+}$ co-doped $\mathrm{CaF}_{2}$ nanocrystals in sol-gel derived glass-ceramics. J. Lumin. 2013, 143, 150-156. [CrossRef]

33. Jiang, Y.; Fan, J.; Jiang, B.; Mao, X.; Zhou, C.; Zhang, L. Structure and optical properties of transparent $\mathrm{Er}^{3+}$-doped $\mathrm{CaF}_{2}$-silica glass ceramic prepared by controllable sol-gel method. Ceram. Int. 2016, 42, 9571-9576. [CrossRef]

34. Chen, D.; Wang, Y.; Yu, Y.; Ma, E.; Zhou, L. Microstructure and luminescence of transparent glass ceramic containing $\mathrm{Er}^{3+}: \mathrm{BaF}_{2}$ nano-crystals. J. Solid State Chem. 2006, 179, 532-537. [CrossRef]

35. Secu, C.E.; Secu, M.; Ghica, C.; Mihut, L. Rare-earth doped sol-gel derived oxyfluoride glass-ceramics: Structural and optical characterization. Opt. Mater. 2011, 33, 1770-1774. [CrossRef]

36. Secu, C.E.; Bartha, C.; Polosan, S.; Secu, M. Thermally activated conversion of a silicate gel to an oxyfluoride glass ceramic: Optical study using $\mathrm{Eu}^{3+}$ probe ion. J. Lumin. 2014, 146, 539-543. [CrossRef]

37. Fujihara, S.; Kitta, S.; Kimura, T. Porous Phosphor thin films of oxyfluoride $\mathrm{SiO}_{2}-\mathrm{BaMgF}_{4}: \mathrm{Eu}^{2+}$ glass-ceramics prepared by sol-gel method. Chem. Lett. 2003, 32, 928-929. [CrossRef]

38. Kitta, S.; Fujihara, S.; Kimura, T. Porous $\mathrm{SiO}_{2}-\mathrm{BaMgF}_{4}: \mathrm{Eu}(\mathrm{II})$ glass-ceramic thin films and their strong blue photoluminescence. J. Sol-Gel Sci. Technol. 2004, 32, 263-266. [CrossRef]

39. Blasse, G.; van den Heuvel, G.P.M.; Van Dijk, T. Energy transfer from $\mathrm{Gd}^{3+}$ to $\mathrm{Tb}^{3+}$ and $\mathrm{Eu}^{3+}$. Chem. Phys. Lett. 1979, 62, 600-602. [CrossRef]

40. Grzyb, T.; Runowski, M.; Lis, S. Facile synthesis, structural and spectroscopic properties of $\mathrm{GdF}_{3}: \mathrm{Ce}^{3+}, \mathrm{Ln}^{3+}$ $\left(\mathrm{Ln}^{3+}=\mathrm{Sm}^{3+}, \mathrm{Eu}^{3+}, \mathrm{Tb}^{3+}, \mathrm{Dy}^{3+}\right)$ nanocrystals with bright multicolor luminescence. J. Lumin. 2014, 154, 479-486. [CrossRef]

41. Pokhrel, M.; Mimun, L.C.; Yust, B.; Kumar, G.A.; Dhanale, A.; Tang, L.; Sardara, D.K. Stokes emission in $\mathrm{GdF}_{3}: \mathrm{Nd}^{3+}$ nanoparticles for bioimaging probes. Nanoscale 2014, 6, 1667-1674. [CrossRef] [PubMed]

42. Fujihara, S.; Tada, M.; Kimura, T. Sol-gel processing of $\mathrm{LaF}_{3}$ thin films. J. Ceram. Soc. JPN 1998, 106, $124-126$. [CrossRef] 
43. Fujihara, S.; Tada, M.; Kimura, T. Formation of $\mathrm{LaF}_{3}$ microcrystals in sol-gel silica. J. Non-Cryst. Solids 1999, 244, 267-274. [CrossRef]

44. Tada, M.; Fujihara, S.; Kimura, T. Sol-gel processing and characterization of alkaline earth and rare-earth fluoride thin films. J. Mater. Res. 1999, 14, 1610-1616. [CrossRef]

45. Fujihara, S.; Kato, T.; Kimura, T. Influence of solution composition on the formation of $\mathrm{SiO}_{2} / \mathrm{LaF}_{3}$ composites in the sol-gel process. J. Mater. Sci. 2000, 35, 2763-2767. [CrossRef]

46. Fujihara, S.; Tada, M.; Kimura, T. Controlling factors for the conversion of trifluoroacetate sols into thin metal fluoride coatings. J. Sol-Gel Sci. Technol. 2000, 19, 311-314. [CrossRef]

47. Fujihara, S.; Kato, T.; Kimura, T. Sol-gel synthesis of silica-based oxyfluoride glass-ceramic thin films: incorporation of $\mathrm{Eu}^{3+}$ activators into crystallites. J. Am. Ceram. Soc. 2001, 84, 2716-2718. [CrossRef]

48. Ribeiro, S.J.L.; Araújo, C.C.; Bueno, L.A.; Gonçalves, R.R.; Messaddeq, Y. Sol-gel Eu ${ }^{3+} / \mathrm{Tm}^{3+}$ doped transparent glass-ceramic waveguides. J. Non-Cryst. Solids 2004, 348, 180-184. [CrossRef]

49. Biswas, A.; Maciel, G.S.; Friend, C.S.; Prasad, P.N. Upconversion properties of a transparent $\mathrm{Er}^{3+}-\mathrm{Yb}^{3+}$ co-doped $\mathrm{LaF}_{3}-\mathrm{SiO}_{2}$ glass-ceramics prepared by sol-gel method. J. Non-Cryst. Solids 2003, 316, 393-397. [CrossRef]

50. Yanes, A.C.; del-Castillo, J.; Méndez-Ramos, J.; Rodríguez, V.D.; Torres, M.E.; Arbiol, J. Luminescence and structural characterization of transparent nanostructured $\mathrm{Eu}^{3+}$-doped $\mathrm{LaF}_{3}-\mathrm{SiO}_{2}$ glass-ceramics prepared by sol-gel method. Opt. Mater. 2007, 9, 999-1003. [CrossRef]

51. Velázquez, J.J.; Yanes, A.C.; del Castillo, J.; Méndez-Ramos, J.; Rodríguez, V.D. Optical properties of $\mathrm{Ho}^{3+}-\mathrm{Yb}^{3+}$ co-doped nanostructured $\mathrm{SiO}_{2}-\mathrm{LaF}_{3}$ glass-ceramics prepared by sol-gel method. Phys. Status Solidi A 2007, 204, 1762-1768. [CrossRef]

52. Méndez-Ramos, J.; Velázquez, J.J.; Yanes, A.C.; del Castillo, J.; Rodríguez, V.D. Up-conversion in nanostructured $\mathrm{Yb}^{3+}-\mathrm{Tm}^{3+}$ co-doped sol-gel derived $\mathrm{SiO}_{2}-\mathrm{LaF}_{3}$ transparent glass-ceramics. Phys. Status Solidi A 2008, 205, 330-334. [CrossRef]

53. Yanes, A.C.; Velázquez, J.J.; del Castillo, J.; Méndez-Ramos, J.; Rodríguez, V.D. Colour tuneability and white light generation in $\mathrm{Yb}^{3+}-\mathrm{Ho}^{3+}-\mathrm{Tm}^{3+}$ co-doped $\mathrm{SiO}_{2}-\mathrm{LaF}_{3}$ nano-glass-ceramics prepared by sol-gel method. J. Sol-Gel Sci. Technol. 2009, 51, 4-9. [CrossRef]

54. Velázquez, J.J.; Rodríguez, V.D.; Yanes, A.C.; del Castillo, J.; Méndez-Ramos, J. Increase in the $\mathrm{Tb}^{3+}$ green emission in $\mathrm{SiO}_{2}-\mathrm{LaF}_{3}$ nano-glass-ceramics by codoping with $\mathrm{Dy}^{3+}$ ions. J. Appl. Phys. 2010, 108, 113530-113536. [CrossRef]

55. Velázquez, J.J.; Rodríguez, V.D.; Yanes, A.C.; del Castillo, J.; Méndez-Ramos, J. Photon down-shifting by energy transfer from $\mathrm{Sm}^{3+}$ to $\mathrm{Eu}^{3+}$ ions in sol-gel $\mathrm{SiO}_{2}-\mathrm{LaF}_{3}$ nano-glass-ceramics for photovoltaics. Appl. Phys. B 2012, 108, 577-583. [CrossRef]

56. Dejneka, M.J. The luminescence and structure of novel transparent oxyfuoride glass-ceramics. J. Non-Cryst. Solids 1998, 239, 149-155. [CrossRef]

57. Luo, W.; Wang, Y.; Cheng, Y.; Bao, F.; Zhou, L. Crystallization and structural evolution of $\mathrm{YF}_{3}-\mathrm{SiO}_{2}$ xerogel. Mater. Sci. Eng. B 2006, 127, 218-223. [CrossRef]

58. Méndez-Ramos, J.; Santana-Alonso, A.; Yanes, A.C.; del Castillo, J.; Rodríguez, V.D. Rare-earth doped $\mathrm{YF}_{3}$ nanocrystals embedded in sol-gel silica glass matrix for white light generation. J. Lumin. 2010, 130, 2508-2511. [CrossRef]

59. Santana-Alonso, A.; Méndez-Ramos, J.; Yanes, A.C.; del Castillo, J.; Rodríguez, V.D. White light up-conversion in transparent sol-gel derived glass-ceramics containing $\mathrm{Yb}^{3+}-\mathrm{Er}^{3+}-\mathrm{Tm}^{3+}$ triply-doped $\mathrm{YF}_{3}$ nanocrystals. Mater. Chem. Phys. 2010, 124, 699-703. [CrossRef]

60. Yanes, A.C.; Santana-Alonso, A.; Méndez-Ramos, J.; del Castillo, J.; Rodríguez, V.D. Novel sol-gel nano-glass-ceramics comprising $\mathrm{Ln}^{3+}$-Doped $\mathrm{YF}_{3}$ nanocrystals: structure and high efficient $\mathrm{UV}$ up-conversion. Adv. Funct. Mater. 2011, 21, 3136-3142. [CrossRef]

61. Chen, D.; Wang, Y.; Yu, Y.; Huang, P. Structure and optical spectroscopy of Eu-doped glass ceramics containing $\mathrm{GdF}_{3}$ nanocrystals. J. Phys. Chem. C 2008, 112, 18943-18947. [CrossRef]

62. Shan, Z.; Chen, D.; Yu, Y.; Huang, P.; Lin, H.; Wang, Y. Luminescence in rare earth-doped transparent glass ceramics containing $\mathrm{GdF}_{3}$ nanocrystals for lighting applications. J. Mater. Sci. 2010, 45, 2775-2779. [CrossRef]

63. Yin, W.; Zhao, L.; Zhou, L.; Gu, Z.; Liu, X.; Tian, G.; Jin, S.; Yan, L.; Ren, W.; Xing, G.; Zhao, Y. Enhanced red emission from $\mathrm{GdF}_{3}: \mathrm{Yb}^{3+}, \mathrm{Er}^{3+}$ upconversion nanocrystals by $\mathrm{Li}^{+}$doping and their application for bioimaging. Chem. Eur. J. 2012, 18, 9239-9245. [CrossRef] [PubMed] 
64. Fujihara, S.; Koji, S.; Kimura, T. Structure and optical properties of (Gd,Eu)F $\mathrm{F}_{3}$-nanocrystallized sol-gel silica films. J. Mater. Chem. 2004, 14, 1331-1335. [CrossRef]

65. Szpikowska-Sroka, B.; Zur, L.; Czoik, R.; Goryczka, T.; Żąłło, M.; Pisarski, W.A. Ultraviolet-to-visible downconversion luminescence in solgel oxyfluoride glass ceramics containing $\mathrm{Eu}^{3+}: \mathrm{GdF}_{3}$ nanocrystals. Opt. Lett. 2014, 39, 3181-3184. [CrossRef] [PubMed]

66. Szpikowska-Sroka, B.; Pawlik, N.; Goryczka, T.; Pisarski, W.A. Influence of silicate sol-gel host matrices and catalyst agents on the luminescent properties of $\mathrm{Eu}^{3+} / \mathrm{Gd}^{3+}$ under different excitation wavelengths. RSC Adv. 2015, 5, 98773-98782. [CrossRef]

67. Pawlik, N.; Szpikowska-Sroka, B.; Sołtys, M.; Pisarski, W.A. Optical properties of silica sol-gel materials singly- and doubly-doped with $\mathrm{Eu}^{3+}$ and $\mathrm{Gd}^{3+}$ ions. J. Rare Earth 2016, 34, 786-795. [CrossRef]

68. Kano, T.; Yamamoto, H.; Otomo, Y. NaLnF $4: \mathrm{Yb}^{3+}, \mathrm{Er}^{3+}$ (Ln: Y, Gd, La): Efficient green-emitting infrared-excited phosphors. J. Electrochem. Soc. 1972, 119, 1561-1564. [CrossRef]

69. Krämer, K.W.; Biner, D.; Frei, G.; Güdel, H.U.; Hehlen, M.P.; Lüthi, S.R. Hexagonal sodium yttrium fluoride based green and blue emitting upconversion phosphors. Chem. Mater. 2004, 16, 1244-1251. [CrossRef]

70. Liu, F.; Ma, E.; Chen, D.; Yu, Y.; Wang, Y. Tunable red-green upconversion luminescence in novel transparent glass ceramics containing Er: $\mathrm{NaYF}_{4}$ nanocrystals. J. Phys. Chem. B 2006, 110, 20843-20846. [CrossRef] [PubMed]

71. De Pablos-Martín, A.; Méndez-Ramos, J.; del Castillo, J.; Durán, A.; Rodríguez, V.D.; Pascual, M.J. Crystallization and up-conversion luminescence properties of $\mathrm{Er}^{3+} / \mathrm{Yb}^{3+}$-doped $\mathrm{NaYF}_{4}$-based nano-glass-ceramics. J. Eur. Ceram. Soc. 2015, 35, 1831-1840. [CrossRef]

72. Yanes, A.C.; Santana-Alonso, A.; Méndez-Ramos, J.; del Castillo, J.; Rodríguez, V.D. Yb ${ }^{3+}-E^{3+}$ co-doped sol-gel transparent nano-glass-ceramics containing $\mathrm{NaYF}_{4}$ nanocrystals for tuneable up-conversion phosphors. J. Alloy. Compd. 2009, 480, 706-710. [CrossRef]

73. Santana-Alonso, A.; Yanes, A.C.; Méndez-Ramos, J.; del Castillo, J.; Rodríguez, V.D. Sol-gel transparent nano-glass-ceramics containing $\mathrm{Eu}^{3+}$-doped $\mathrm{NaYF}_{4}$ nanocrystals. J. Non-Cryst. Solids 2010, 356, 933-936. [CrossRef]

74. Santana-Alonso, A.; Méndez-Ramos, J.; Yanes, A.C.; del Castillo, J.; Rodríguez, V.D. Up-conversion in sol-gel derived nano-glass-ceramics comprising $\mathrm{NaYF}_{4}$ nano-crystals doped with $\mathrm{Yb}^{3+}, \mathrm{Ho}^{3+}$ and $\mathrm{Tm}^{3+}$. Opt. Mater. 2010, 32, 903-908. [CrossRef]

75. Méndez-Ramos, J.; Yanes, A.C.; Santana-Alonso, A.; del Castillo, J.; Rodríguez, V.D. Colour tuneability in sol-gel nano-glass-ceramics comprising $\mathrm{Yb}^{3+}-\mathrm{Er}^{3+}-\mathrm{Tm}^{3+}$ Co-Doped $\mathrm{NaYF}_{4}$ nanocrystals. J. Nanosci. Nanotechno. 2010, 10, 1273-1277. [CrossRef]

76. Méndez-Ramos, J.; Yanes, A.C.; Santana-Alonso, A.; del Castillo, J. Highly efficient up-conversion and bright white light in RE co-doped $\mathrm{KYF}_{4}$ nanocrystals in sol-gel silica matrix. Chem. Phys. Lett. 2013, 555, 196-201. [CrossRef]

77. Yanes, A.C.; Santana-Alonso, A.; Méndez-Ramos, J.; del Castillo, J. Structure and intense UV up-conversion emissions in $\mathrm{RE}^{3+}$-doped sol-gel glass-ceramics containing $\mathrm{KYF}_{4}$ nanocrystals. Appl. Phys. B 2013, 113, 589-596. [CrossRef]

78. Del Castillo, J.; Yanes, A.C.; Santana-Alonso, A.; Méndez-Ramos, J. Efficient dual-wavelength excitation of $\mathrm{Tb}^{3+}$ emission in rare-earth doped $\mathrm{KYF}_{4}$ cubic nanocrystals dispersed in silica sol-gel matrix. Opt. Mater. 2014, 37, 511-515. [CrossRef]

79. Yanes, A.C.; del Castillo, J. Enhanced emission via energy transfer in RE co-doped $\mathrm{SiO}_{2}-\mathrm{KYF}_{4}$ nano-glass-ceramics for white LEDs. J. Alloy. Compd. 2016, 658, 170-178. [CrossRef]

80. Deng, D.; Xu, S.; Zhao, S.; Li, C.; Wang, H.; Ju, H. Enhancement of upconversion luminescence in $\mathrm{Tm}^{3+} / \mathrm{Er}^{3+} / \mathrm{Yb}^{3+}$-codoped glass ceramic containing LiYF 4 nanocrystals. J. Lumin. 2009, 129, 1266-1270. [CrossRef]

81. Kawamura, G.; Yoshimura, R.; Ota, K.; Oh, S.Y.; Hakiri, N.; Muto, H.; Hayakawa, T.; Matsuda, A. A unique approach to characterization of sol-gel-derived rare-earth-doped oxyfluoride glass-ceramics. J. Am. Ceram. Soc. 2013, 96, 476-480. [CrossRef]

82. Secu, C.E.; Negrea, R.F.; Secu, M. Eu ${ }^{3+}$ probe ion for rare-earth dopant site structure in sol-gel derived LiYF 4 oxyfluoride glass-ceramic. Opt. Mater. 2013, 35, 2456-2460. [CrossRef] 
83. Kawamura, G.; Yoshimura, R.; Ota, K.; Oh, S.Y.; Muto, H.; Hayakawa, T.; Matsuda, A. Extraction of $\mathrm{Nd}^{3+}$-doped $\mathrm{LiYF}_{4}$ phosphor from sol-gel-derived oxyfluoride glass ceramics by hydrofluoric acid treatment. Opt. Mater. 2013, 45, 1879-1881. [CrossRef]

84. Secu, M.; Secu, C.E. Up-conversion luminescence of $\mathrm{Er}^{3+} / \mathrm{Yb}^{3+}$ co-doped $\mathrm{LiYF}_{4}$ nanocrystals in sol-gel derived oxyfluoride glass-ceramics. J. Non-Cryst. Solids 2015, 426, 78-82. [CrossRef]

85. Del Castillo, J.; Yanes, A.C.; Abe, S.; Smet, P.F. Site selective spectroscopy in $\mathrm{BaYF}_{5}: \mathrm{RE}^{3+}(\mathrm{RE}=\mathrm{Eu}, \mathrm{Sm})$ nano-glass-ceramics. J. Alloy. Compd. 2015, 635, 136-141. [CrossRef]

86. Del Castillo, J.; Yanes, A.C. Bright luminescence of $\mathrm{Gd}^{3+}$ sensitized $\mathrm{RE}^{3+}$-doped $\mathrm{SiO}_{2}-\mathrm{BaGdF}_{5}$ glass-ceramics for UV-LEDs colour conversion. J. Alloy. Compd. 2017, 695, 3736-3743. [CrossRef]

87. Chiodini, N.; Paleari, A.; DiMartino, D.; Spinolo, G. $\mathrm{SnO}_{2}$ nanocrystals in $\mathrm{SiO}_{2}$ : A wide-band-gap quantum-dot system. Appl. Phys. Lett. 2022, 81, 1702-1704. [CrossRef]

88. Du, J.; Zhao, R.; Xie, Y.; Li, J. Size-controlled synthesis of $\mathrm{SnO}_{2}$ quantum dots and their gas-sensing performance. Appl Surf. Sci. 2015, 346, 256-262. [CrossRef]

89. Nogami, M.; Enomoto, T.; Hayakawa, T. Enhanced fluorescence of $\mathrm{Eu}^{3+}$ induced by energy transfer from nanosized $\mathrm{SnO}_{2}$ crystals in glass. J. Lumin. 2002, 97, 147-152. [CrossRef]

90. Chiodini, N.; Paleari, A.; Spinolo, G.; Crespi, P. Photorefractivity in $\mathrm{SiO}_{2}: \mathrm{SnO}_{2}$ glass-ceramics by visible light. J. Non-Cryst. Solids 2003, 322, 266-271. [CrossRef]

91. Yanes, A.C.; del Castillo, J.; Torres, M.; Peraza, J.; Rodríguez, V.D.; Méndez-Ramos, J. Nanocrystal-size selective spectroscopy in $\mathrm{SnO}^{2}: \mathrm{Eu}^{3+}$ semiconductor quantum dots. Appl. Phys. Lett. 2004, 85, 2343-2345. [CrossRef]

92. Del Castillo, J.; Rodríguez, V.D.; Yanes, A.C.; Méndez-Ramos, J.; Torres, M.E. Luminescent properties of transparent nanostructured $\mathrm{Eu}^{3+}$ doped $\mathrm{SnO}_{2}-\mathrm{SiO}_{2}$ glass-ceramics prepared by the sol-gel method. Nanotechnology 2005, 16, S300-S303. [CrossRef]

93. Del Castillo, J.; Yanes, A.C.; Velázquez, J.J.; Méndez-Ramos, J.; Rodríguez, V.D. Luminescent properties of $\mathrm{Eu}^{3+}-\mathrm{Tb}^{3+}$-doped $\mathrm{SiO}_{2}-\mathrm{SnO}_{2}$-based nano-glass-ceramics prepared by sol-gel method. J. Alloy. Compd. 2009, 473, 571-575. [CrossRef]

94. Morais, E.A.; Ribeiro, S.J.L.; Scalvi, L.V.A.; Santilli, C.V.; Ruggiero, L.O.; Pulcinelli, S.H.; Messadeq, Y. Optical characteristics of $\mathrm{Er}^{3+}-\mathrm{Yb}^{3+}$ doped $\mathrm{SnO}_{2}$ xerogels. J. Alloy. Compd. 2002, 344, 217-220. [CrossRef]

95. Van Tran, T.T.; Si Bui, T.; Turrell, S.; Capoen, B.; Roussel, P.; Bouazaoui, M.; Ferrari, M.; Cristini, O.; Kinowski, C. Controlled $\mathrm{SnO}_{2}$ nanocrystal growth in $\mathrm{SiO}_{2}-\mathrm{SnO}_{2}$ glass-ceramic monoliths. J. Raman Spectrosc. 2012, 43, 869-875. [CrossRef]

96. Van Tran, T.T.; Turrell, S.; Capoen, B.; Le Van, H.; Ferrari, M.; Ristic, D.; Boussekey, L.; Kinowski, C. Environment segregation of $\mathrm{Er}^{3+}$ emission in bulk sol-gel-derived $\mathrm{SiO}_{2}-\mathrm{SnO}_{2}$ glass ceramics. J. Mater. Sci. 2014, 49, 8226-8233. [CrossRef]

97. Gonçalves, R.R.; Messaddeq, Y.; Chiasera, A.; Jestin, Y.; Ferrari, M.; Ribeiro, S.J.L. Erbium-activated silica-zirconia planar waveguides prepared by sol-gel route. Thin Solid Films 2008, 516, 3094-3097. [CrossRef]

98. Gonçalves, R.R.; Guimarães, J.J.; Ferrari, J.L.; Maia, L.J.Q.; Ribeiro, S.J.L. Active planar waveguides based on sol-gel $\mathrm{Er}^{3+}$-doped $\mathrm{SiO}_{2}-\mathrm{ZrO}_{2}$ for photonic applications: Morphological, structural and optical properties. J. Non-Cryst. Solids 2008, 354, 4846-4851. [CrossRef]

99. Suhaimi, N.F.M.; Rashid, S.N.M.; Junit, N.F.H.M.; Iznie Razakia, N.; Abd-Rahmana, M.K.; Ferrari, M. Effect of Zirconia in $\mathrm{Er}^{3+}$-doped $\mathrm{SiO}_{2}-\mathrm{ZrO}_{2}$ for planar waveguide laser. In Proceedings of the $2012 \mathrm{IEEE} 3 \mathrm{rd}$ International Conference on Photonics (ICP), Penang, Malaysia, 1-3 October 2012.

100. Dos Santos Cunha, C.; Ferrari, J.L.; de Oliveira, D.C.; Maia, L.J.Q.; Gomes, A.S.L.; Ribeiro, S.J.L.; Gonçalves, R.R. NIR luminescent $\mathrm{Er}^{3+} / \mathrm{Yb}^{3+}$ co-doped $\mathrm{SiO}_{2}-\mathrm{ZrO}_{2}$ nanostructured planar and channel waveguides: Optical and structural properties. Mater. Chem. Phys. 2012, 136, 120-129. [CrossRef]

101. Ribeiro, S.J.L.; Messaddeq, Y.; Gonçalves, R.R.; Ferrari, M.; Montagna, M.; Aegerter, M.A. Low optical loss planar waveguides prepared in an organic-inorganic hybrid system. Appl. Phys. Lett. 2000, 77, 3502-3504. [CrossRef]

102. Jestin, Y.; Armellini, C.; Chiappini, A.; Chiaser, A.; Ferrari, M.; Goyes, C.; Montagna, M.; Moser, E.; Nunzi Conti, G.; Pelli, S.; et al. Erbium activated $\mathrm{HfO}_{2}$ based glass-ceramics waveguides for photonics. J. Non-Cryst. Solids 2007, 353, 494-497. [CrossRef]

103. Ferrari, J.L.; Lima, K.O.; Maia, L.J.Q.; Ribeiro, S.J.L.; Gonçalves, R.R. Structural and spectroscopic properties of luminescent $\mathrm{Er}^{3+}$-Doped $\mathrm{SiO}_{2}-\mathrm{Ta}_{2} \mathrm{O}_{5}$ nanocomposites. J. Am. Ceram. Soc. 2011, 94, 1230-1237. [CrossRef] 
104. Aquino, F.T.; Ferrari, J.L.; Ribeiro, S.J.L.; Ferrier, A.; Goldner, P.; Gonçalves, R.R. Broadband NIR emission in novel sol-gel $\mathrm{Er}^{3+}$-doped $\mathrm{SiO}_{2}-\mathrm{Nb}_{2} \mathrm{O}_{5}$ glass ceramic planar waveguides for photonic applications. Opt. Mater. 2013, 35, 387-396. [CrossRef]

105. Secu, M.; Secu, C.E.; Bartha, C. Crystallization and luminescence properties of a new Eu ${ }^{3+}$-doped LaOCl nano-glass-ceramic. J. Eur. Ceram. Soc. 2016, 36, 203-207. [CrossRef]

106. Innocenzi, P.; Abdirashid, M.O.; Guglielmi, M. Structure and properties of sol-gel coatings from methyltriethoxysilane and tetraethoxysilane. J. Sol-Gel Sci. Technol. 1994, 3, 47-55. [CrossRef]

107. Ravel, B.; Newville, M. ATHENA, ARTEMIS, HEPHAESTUS: Data analysis for X-ray absorption spectroscopy using IFEFFIT. J. Synchrotron Radiat. 2005, 12, 537-541. [CrossRef] [PubMed]

108. Ma, Y.; Lee, H.R.; Tsuru, T. Study on preparation and hydrophobicity of MTES derived silica sol and gel. Adv. Mater. Res. 2012, 535-537, 2563-2566. [CrossRef]

109. Jia, Y.Q. Crystal Radii and effective ionic radii of the rare earth ions. J. Sol. State Chem. 1991, 95, $184-187$. [CrossRef]

110. Gorni, G.; Pascual, M.J.; Caballero, A.; Velázquez, J.J.; Mosa, J.; Castro, Y.; Durán, A. Crystallization mechanism in sol-gel oxyfluoride glass-ceramics. J. Non-Cryst. Solids 2018, accepted.

111. Gorni, G.; Balda, R.; Ferández, J.; Velázquez, J.J.; Pascual, L.; Mosa, J.; Durán, A.; Castro, Y. 80SiO $\mathrm{S}_{2}-20 \mathrm{LaF}_{3}$ oxyfluoride glass ceramic coatings doped with $\mathrm{Nd}^{3+}$ for optical applications. Int. J. Appl. Glass Sci. 2017, in press. [CrossRef]

112. Velázquez, J.J.; Mosa, J.; Gorni, G.; Balda, R.; Ferández, J.; Pascual, L.; Durán, A.; Castro, Y. Transparent $\mathrm{SiO}_{2}-\mathrm{GdF}_{3}$ sol-gel nano-glass ceramics for optical applications. J. Sol-Gel Sci. Technol. 2018, under-review.

113. Chen, D.; Yu, Y.; Huang, P.; Wang, Y. Nanocrystallization of lanthanide trifluoride in an aluminosilicate glass matrix: Dimorphism and rare earth partition. CrystEngComm 2009, 11, 1686-1690. [CrossRef]

114. Bartha, C.; Secu, C.E.; Matei, E.; Secu, M. Crystallization kinetics mechanism investigation of sol-gel-derived $\mathrm{NaYF}_{4}$ :(Yb,Er) up-converting phosphors. CrystEngComm 2017, 19, 4992-5000. [CrossRef]

115. Agarwal, B.K.; Verma, L.P. A rule for chemical shifts of X-ray absorption edges. J. Phys. C Solid State 1970, 3 , 535-537. [CrossRef]

116. Gorni, G.; Velázquez, J.J.; Mather, G.C.; Durán, A.; Chen, G.; Sundararaja, M.; Balda, R.; Ferández, J.; Pascual, M.J. Selective excitation in transparent oxyfluoride glass-ceramics doped with $\mathrm{Nd}^{3+}$. J. Eur. Ceram. Soc. 2017, 37, 1695-1706. [CrossRef] 